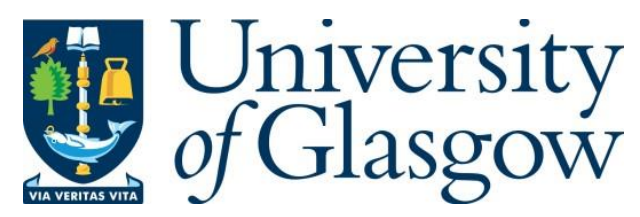

Fotouhi, M., Jalalvand, M. and Wisnom, M. R. (2018) Notch insensitive orientationdispersed pseudo-ductile thin-ply carbon/glass hybrid laminates. Composites Part A: Applied Science and Manufacturing, 110, pp. 29-44.

There may be differences between this version and the published version. You are advised to consult the publisher's version if you wish to cite from it.

http://eprints.gla.ac.uk/196771/

Deposited on: 19 September 2019

Enlighten - Research publications by members of the University of Glasgow http://eprints.gla.ac.uk 


\title{
Notch insensitive orientation-dispersed pseudo-ductile thin-ply carbon/glass hybrid laminates
}

\author{
Mohamad Fotouhi ${ }^{1,2}$, Meisam Jalalvand ${ }^{2,3}$, Michael R. Wisnom ${ }^{2}$ \\ ${ }^{1}$ Department of Design and Mathematics, the University of the West of England, Bristol BS16 1QY, UK \\ ${ }^{2}$ Bristol Composites Institute (ACCIS), University of Bristol, Bristol BS8 1TR, UK \\ ${ }^{3}$ Department of Mechanical and Aerospace Engineering, University of Strathclyde, 75 Montrose Street, Glasgow, \\ G1 1XJ, UK
}

\begin{abstract}
Notch sensitivity, free edge delamination and brittle failure are limiting factors for the wider use of conventional composite laminates. In our previous study, a hybrid layup concept with the different materials blocked together but with dispersed orientations was successfully used to design pseudo-ductile hybrid composites with no free-edge delamination. This study introduces a comprehensive set of designed and characterised orientation-dispersed pseudoductile thin-ply hybrid composites to address notch sensitivity, another important limiting factor in conventional composite laminates. Un-notched, open-hole and sharp notched tension tests were performed on three different thin-ply carbon/glass hybrid configurations. The investigated laminates showed a successful pseudo-ductile un-notched behaviour with improved notch-insensitivity and suppression of free-edge delamination that was an undesirable damage mode in previously investigated hybrids with plies of the same orientation blocked together. This notch insensitivity results from subcritical damage in the laminates due to the pseudo-ductile damage mechanisms, i.e. dispersed delamination and fragmentation. These damage mechanisms can eliminate stress concentrations near the notch and suppress the conventional damage mechanisms that govern the notched response of the laminates.
\end{abstract}

\section{Introduction}

Composite materials have high specific stiffness and strength and their use has been increasing in engineering applications. However, cut-outs and holes are necessary for the geometry and 
assembly of composite sub-components and they weaken the laminate. Due to the importance of the notched strength in the design of composite structures, considerable research has been undertaken to investigate the notched behaviour of these materials [1-5].

Many parameters such as notch size and geometry, laminate size and thickness, machining quality, ply orientation and thickness, and material constituents affect the complex failure mechanisms during the loading of notched laminates [6-14]. These parameters change the damage mechanisms during loading and have a profound effect on laminate strength and notch sensitivity. In some cases $[8,9,15]$ a positive effect on specimen ultimate strength was reported due to the damage growth prior to catastrophic failure, but conventional laminates always show some degree of notch sensitivity.

Thin-ply composites have been reported to show enhanced un-notched strength in tension, potential for improved compressive unnotched and notched strength and higher fatigue resistance [16-21]. However, due to the lower local stress redistribution in the vicinity of the notch, thin-ply laminates have a negative impact in notched structures loaded in tension that results in earlier brittle failure of the composites [20]. Early work on pseudo-ductile composites [22-28] reported that by combining different types of thin-ply carbon fibres and standard glass fibres, an optimised gradual failure process can be achieved in tension that can avoid catastrophic failure. In these studies, unidirectional hybrids were used to generate pseudoductile behaviour, with the concept then applied on quasi-isotropic (QI) laminates [29-31]. It was found that by changing the relative and absolute thickness of the carbon layer as well as the material properties, three damage mechanisms, i.e. low strain material failure/fragmentation, delamination, high strain material failure, or a combination of these damage modes may occur before the final failure.

Un-notched and notched tensile response and damage accumulation of multi-directional carbon/epoxy hybrid laminates made from ultra-high modulus and high strength have been 
studied [29]. Locally active fragmentation in the notched QI specimens demonstrated a notchinsensitive behaviour, but a significant free edge delamination occurred due to the choice of the UD hybrid sublaminates that were used as the building blocks of the hybrid laminates. This is due to high thickness of each sub laminate in this orientation-blocked concept, resulting in high-energy release rates for free-edge delamination. A different orientation-dispersed concept was recently introduced [30] in which non-hybrid multi-directional sublaminates with different fibre types are stacked up to solve the free edge delamination by reducing the thickness of material of the same orientation. It was shown that the orientation-dispersed concept significantly reduces the energy release rate associated with stresses at the free edges of the tensile samples and therefore supresses free-edge delamination.

This paper presents a comprehensive set of designed and characterised orientation-dispersed pseudo-ductile thin-ply hybrid laminates to improve notch insensitivity and to avoid free edge delamination in tension. The introduced thin-ply hybrid configurations show pseudo-ductile damage mechanisms that suppress the mechanisms that govern the notched response of conventional laminates.

\section{Pseudo-ductility features}

Fig. 1 shows a schematic of the stress-strain graph for a thin-ply hybrid with pseudo-ductile behaviour. The five important features of the nonlinear stress-strain curve are as follows:

(i) Pseudo-ductile strain $\left(\varepsilon_{\mathrm{pd}}\right)$ which is the extra strain obtained due to gradual failure. The $\varepsilon_{\mathrm{pd}}$ is defined here as the extra strain between the final failure point and the initial slope line at the failure stress level as shown in Fig. 1.

(ii) Pseudo-yield stress $\left(\sigma_{\mathrm{py}}\right)$ which is the stress level at which the tensile response has a significant deviation from the initial linear elastic behaviour. 
(iii) Pseudo-yield strain $\left(\varepsilon_{\mathrm{py}}\right)$ which is the strain level at which the tensile response deviates significantly from the initial linear elastic behaviour. Pseudo-yield strain values are defined as the intersection of two lines fitted to the stress-strain graph before and after the knee point that marks the establishment of the fragmentation process.

(iv) $\varepsilon_{\mathrm{f}}$ and $\sigma_{\mathrm{f}}$ are the final failure strain and stress values at which fibre failure of the high strain material occurs, respectively.

(v) The hybrid effect is defined here as the enhancement in strain and stress to failure of the low strain fibres in the thin-ply hybrid composite, compared to those obtained in hybrid specimens with thick carbon plies where it was found that there is no hybrid effect [26].

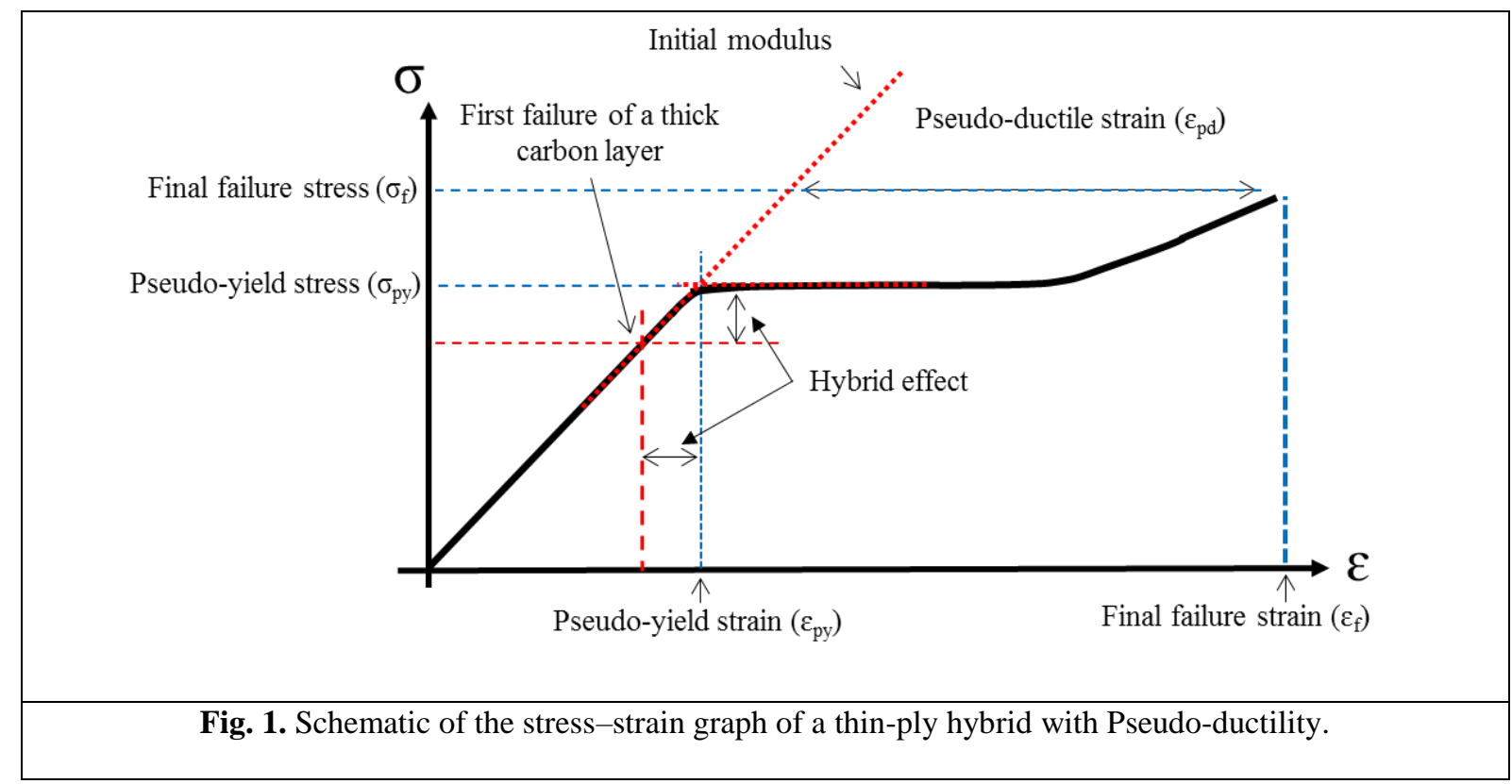

\section{Experimental procedures}

\subsection{Materials and specimen design}

Properties of the 4 types of prepregs that were used in the experimental design are listed in table 1. Some of these are estimates, but they are sufficient to enable appropriate combinations 
of materials to be selected. Unidirectional (UD) Xstrand-glass/513 epoxy prepreg manufactured by North Thin-ply Technology and UD S-glass/913 epoxy prepreg supplied by Hexcel were used as the high strain materials of the hybrid laminates. The low strain materials were thin UD carbon prepregs, M46JB-carbon/120EP-513 epoxy from North Thin-ply Technology and T300/epoxy (SkyFlex USN020A) from SK Chemicals (South Korea).

Table 1: Properties of the applied prepregs.

\begin{tabular}{|c|c|c|c|c|}
\hline Prepreg type & Xstrand-glass/513 epoxy & $\begin{array}{c}\text { M46JB-carbon/513 epoxy } \\
{[34]}\end{array}$ & S-glass/913epoxy [27] & $\mathrm{T} 300 / 120^{\circ} \mathrm{c}$ epoxy ${ }^{\mathrm{e}}$ \\
\hline Fibre modulus (GPa) & $96^{\mathrm{a}}$ & 436 & 88 & $230^{f}$ \\
\hline $\begin{array}{l}\text { Prepreg fibre direction } \\
\text { Modulus, E11 (GPa) }\end{array}$ & $45.5^{\mathrm{b}}$ & 233 & 45.7 & 101.7 \\
\hline $\begin{array}{l}\text { Prepreg transverse direction } \\
\text { Modulus, E22 (GPa) }\end{array}$ & $15.4[32]$ & $7.0^{\mathrm{d}}$ & - & - \\
\hline G12 & 4.34 & $4.66^{\mathrm{d}}$ & - & - \\
\hline v12 & 0.3 & $0.314^{\mathrm{d}}$ & - & - \\
\hline$\alpha 11(\mathrm{E}-6 / \mathrm{K})$ & 3.85 & $1^{\mathrm{d}}$ & - & - \\
\hline$\alpha 22(\mathrm{E}-6 / \mathrm{K})$ & 45 [33] & $35^{\mathrm{d}}$ & - & - \\
\hline Fibre failure strain (\%) & $2.5^{\mathrm{b}}$ & 0.9 & 5.5 & 1.5 \\
\hline Cured nominal thickness (mm) & $0.05^{\mathrm{b}}$ & 0.029 & 0.155 & 0.029 \\
\hline Fibre mass per unit area $\left(\mathrm{g} / \mathrm{m}^{2}\right)$ & $75^{\mathrm{a}}$ & 29 & 190 & 22 \\
\hline Fibre volume fraction (\%) & $42^{\mathrm{c}}$ & 53 & 50 & 43 \\
\hline Supplier & $\begin{array}{l}\text { North Thin-ply } \\
\text { Technology }\end{array}$ & North Thin-ply Technology & Hexcel & Sky Flex \\
\hline
\end{tabular}

a) Supplier's provided information.

b) Measured on 16 ply UD laminates, specimens failed explosively at the end tabs.

c) Estimated based on UD tensile strength from the experimental data measured on 16 ply UD laminates.

d) These values are from the data sheet for M40 Carbon/epoxy prepreg with the same resin that has relatively similar properties as M46 Carbon/epoxy prepreg.

e) These values are experimentally measured from a SkyFlex USN020A prepreg with the same elastic modulus but with a similar type of fibre made by a different manufacturer [24].

f) This value is based on T300 Data Sheet [35]. 
The investigated layups are schematically illustrated in Fig. 2 and listed in Table 2, where, in the layup column, the first numbers show the orientations of the sub-laminates in degrees. AP is the abbreviation of Angle Ply. The non-zero degree layers in the $\pm 60 \mathrm{QI} / \mathrm{Hexcel}, \pm 60 \mathrm{QI} / \mathrm{North}$ and $\pm 30 \mathrm{AP} /$ North laminates are $\pm 60^{\circ}, \pm 60^{\circ}$ and $\pm 30^{\circ}$, respectively. The (1) and (2) refer to the number of separate blocks of carbon in the North layups, i.e. (1) has a single block of 6 carbon plies, whereas (2) has two blocks of 3 plies each.

Table 2: Investigated cases.

\begin{tabular}{|c|c|c|}
\hline Specimen type & Layup & $\begin{array}{l}\text { Laminate thickness } \\
\text { [mm] }\end{array}$ \\
\hline \pm 30 AP/North (1) & $\begin{array}{c}{\left[\left(0_{\mathrm{X} \text { strand-glass }} /-30_{\mathrm{X} \text { strand-glass }} / 30_{\mathrm{X} \text { strand-glass }}\right)_{2} /\left(0_{\mathrm{M} 46 \mathrm{JB}-\text { carbon }} /-30_{\mathrm{M} 46 \mathrm{JB}-\text { carbon }} / 30_{\mathrm{M} 46 \mathrm{JB}-}\right.\right.} \\
\text { carbon })]_{\mathrm{s}}\end{array}$ & 0.78 \\
\hline $\pm 30 \mathrm{AP} /$ North (2) & $\begin{array}{c}{\left[\left(0_{\mathrm{X} \text { strand-glass }} /-30_{\mathrm{X} \text { strand-glass }} / 30_{\mathrm{X} \text { strand-glass }}\right) /\left(0_{\mathrm{M} 46 \mathrm{JB}-\text { carbon }} /-30_{\mathrm{M} 46 \mathrm{JB}-\text { carbon }} / 30_{\mathrm{M} 46 \mathrm{JB}-}\right.\right.} \\
\left.\text { carbon }) /\left(0_{\mathrm{X} \text { strand-glass }} /-30_{\text {Xstrand-glass }} / 30_{\mathrm{X} \text { strand-glass }}\right)\right]_{\mathrm{s}}\end{array}$ & 0.78 \\
\hline $\pm 60 \mathrm{QI} /$ North $(1)$ & {$\left[\left(0_{\mathrm{X} \text { strand-glass }} /-60_{\mathrm{X} \text { strand-glass }} / 60_{\mathrm{X} \text { strand-glass }}\right)_{2} /\left(0_{\mathrm{M} 46 \mathrm{JB}-\text { carbon }} /-60_{\mathrm{M} 46 \mathrm{JB}-\text { carbon }} / 60_{\mathrm{M} 46 \mathrm{JB}-\text { carbon }}\right)\right]_{\mathrm{s}}$} & 0.78 \\
\hline $\pm 60 \mathrm{QI} /$ North (2) & $\begin{array}{c}{\left[\left(0_{\mathrm{X} \text { strand-glass }} /-60_{\mathrm{X} \text { strand-glass }} / 60_{\mathrm{X} \text { strand-glass }}\right) /\left(0_{\mathrm{C}-\mathrm{M} 46 \mathrm{JB}} /-60_{\mathrm{C}-\mathrm{M} 46 \mathrm{JB}} / 60_{\mathrm{C}-\mathrm{M} 46 \mathrm{JB}}\right) /\left(0_{\mathrm{X} \text { strand- }}\right.\right.} \\
\text { glass }\end{array}$ & 0.78 \\
\hline $\pm 60 \mathrm{QI} / \mathrm{Hexcel}$ & {$\left[60_{\text {S-glass }} /-60_{\text {S-glass }} / 0_{\text {S-glass }} / 0_{\text {T300-carbon }} / 60_{\mathrm{T} 300-\text { carbon }} /-60_{\mathrm{T} 300-c a r b o n}\right]_{\mathrm{S}}$} & 1.10 \\
\hline
\end{tabular}




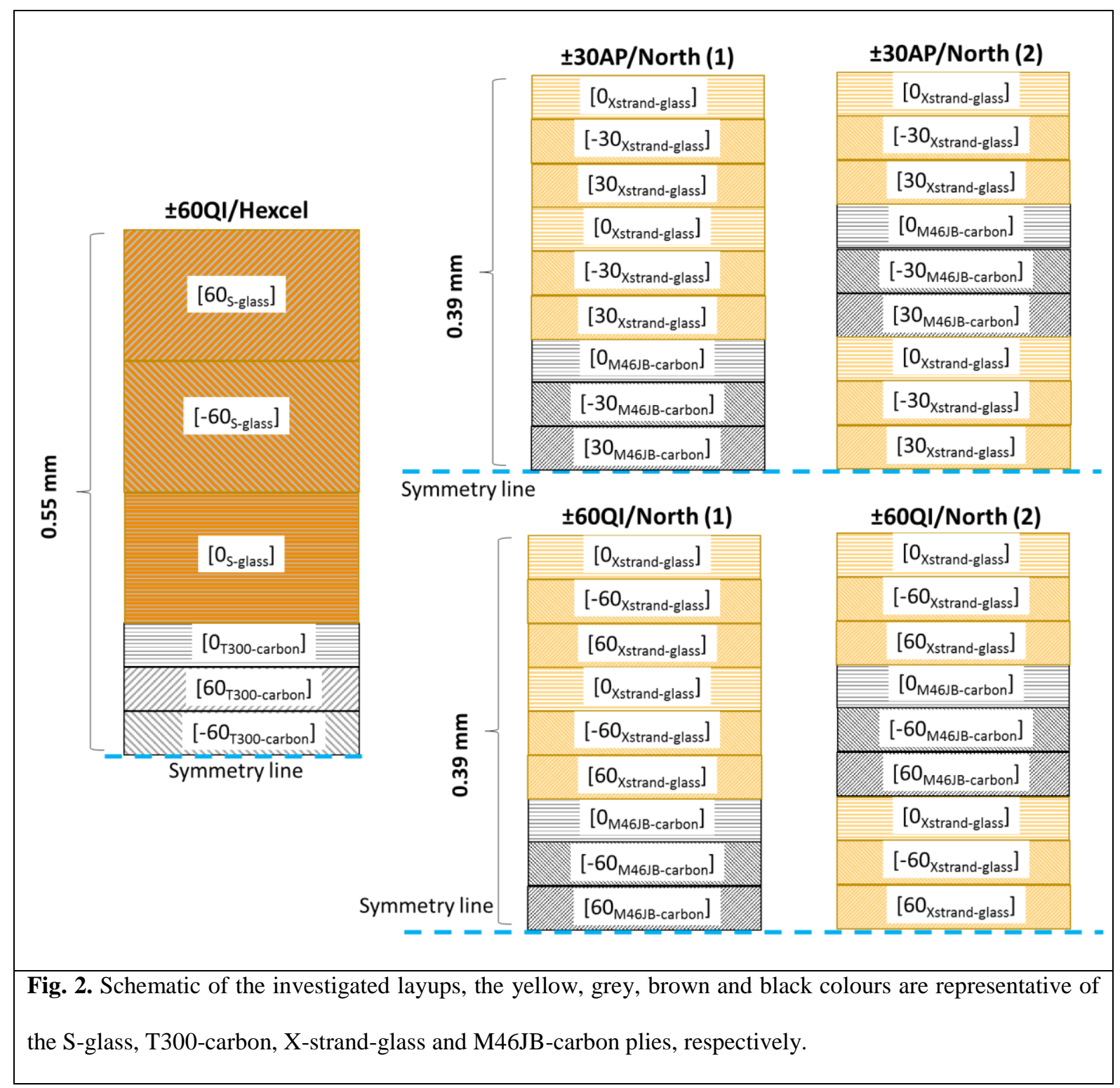

The layups were designed in a similar way as the previously investigated pseudo-ductile QI laminates [30], using damage mode maps and choosing appropriate values of absolute and relative thicknesses of the carbon fibre plies. Choosing the appropriate values suppresses catastrophic fibre failure and delamination and results in pseudo-ductile damage mechanisms (i) fragmentation in the carbon plies and (ii) local delamination. The calculations were done by homogenising the multi-directional glass and carbon sub-laminates, using Classical Laminate Theory. The failure strain of the homogenised materials was assumed to be equal to the fibre failure strain of the $0^{\circ}$ layers. This is an acceptable assumption as the stiffness reduction in the 
deterioration process of the homogenised QI laminate is mainly due to $0^{\circ}$ carbon layer fragmentation and the final failure of the QI glass is because of $0^{\circ}$ glass failure. Although this assumption may not be completely accurate due to possible hybrid effects, it is a reasonable basis to design the configurations. Most of the strength and stiffness of each layer is coming from the $0^{\circ}$ layers and fragmentation/failure of this layer means a big drop in the stiffness of the remaining parts or failure of the whole laminate. Although the fracture toughness of the investigated hybrid interfaces was not characterised directly, our previous experiments, on similar UD hybrid materials comprising the same combinations of epoxy matrix systems as those of this study [24, 29 and 36], indicated that the Hexcel and Sky Flex prepregs have higher mode II toughness $\left(\mathrm{G}_{\mathrm{II}} \sim 1 \mathrm{~N} / \mathrm{mm}\right)$ than those of the North Thin-ply Technology prepregs $\left(\mathrm{G}_{\text {IIc }} \sim 0.7 \mathrm{~N} / \mathrm{mm}\right)$. Therefore, interfacial fracture toughness values between the glass and carbon layers, $\mathrm{G}_{\mathrm{IIc}}$, were assumed to be $1 \mathrm{~N} / \mathrm{mm}$ and $0.7 \mathrm{~N} / \mathrm{mm}$ for the Hexcel and North configurations, respectively.

The resulting damage mode maps with the calculated boundaries between the different regions are illustrated in Fig. 3. The terms "Relative carbon thickness" and "Carbon thickness" are referring to the thickness of the carbon layers divided to the total thickness of the laminate, and the absolute thickness of the carbon layers that are sandwiched between the glass layers, respectively. The colours represent the expected amount of pseudo-ductile strain. The thickness and proportion of carbon plies in the $\pm 30 \mathrm{AP} /$ North (2), $\pm 60 \mathrm{QI} / \mathrm{North}(1)$ and $\pm 60 \mathrm{QI} / \mathrm{Hexcel}$ configurations are in the Fragmentation and Dispersed Delamination (Frag. \& Del.) regions. Therefore, the damage scenarios in these laminates are expected to be fragmentation in the low strain material followed by dispersed delamination and then high strain material failure. For the $\pm 60 \mathrm{QI} /$ North (2), multiple fractures in the low strain material and then high strain material failure are predicted by the damage mode map. The $\pm 30 \mathrm{AP} /$ North (1) laminate is in the Catastrophic Del. region and a premature failure of the high strain material is expected. Even 
though the designed $\pm 30 \mathrm{AP} / \mathrm{North}(1)$ and $\pm 60 \mathrm{QI} /$ North (2) laminates did not look promising regarding the desirable pseudo-ductility, they were selected to have a good set of experimental data and to compare their behaviour with the other notched and un-notched designed configurations. Please note that the damage mode maps are obtained for the un-notched samples and damage mechanisms in the notched configurations might be slightly different.

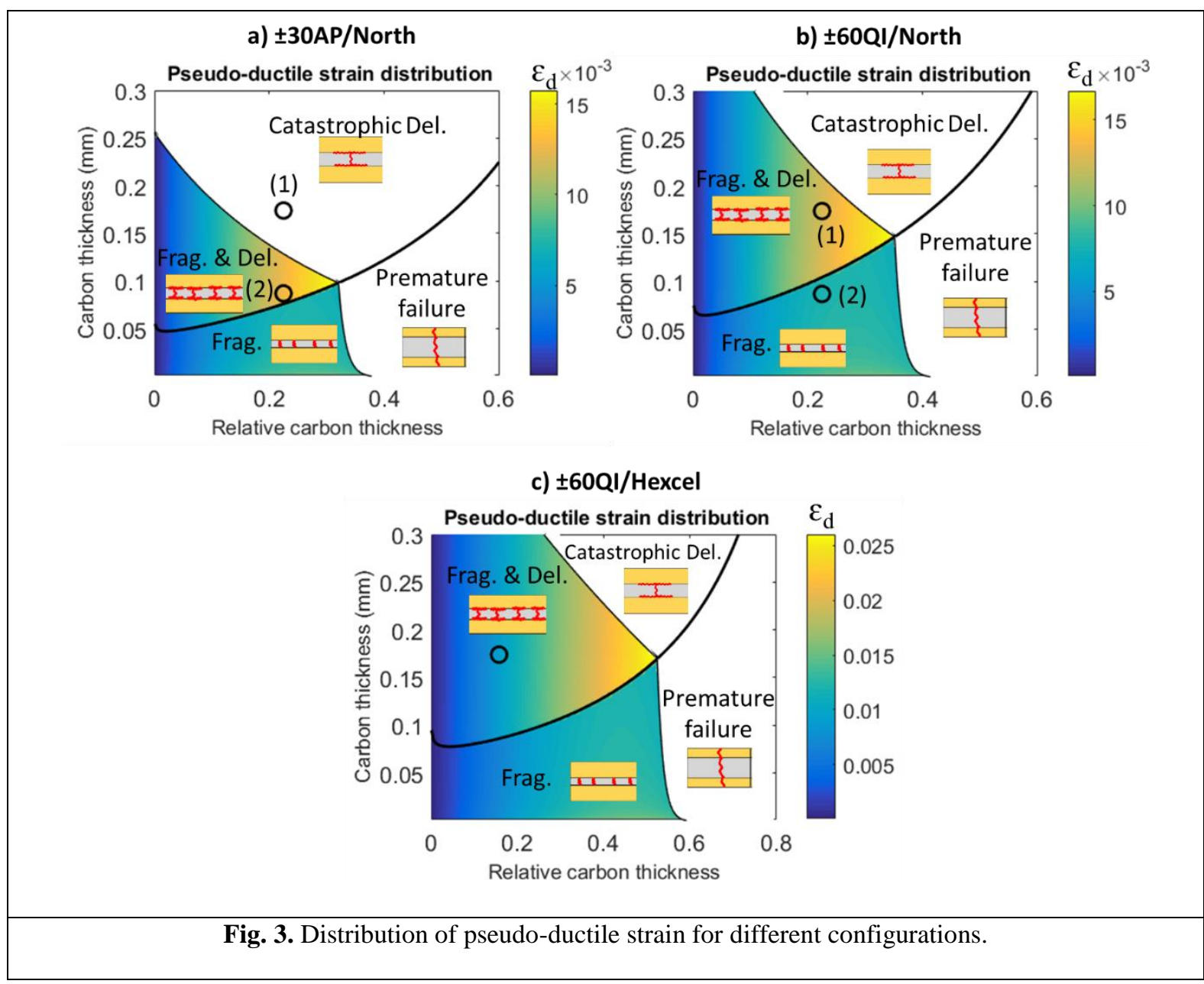

\subsection{Specimen manufacturing}

The resin systems in the prepregs were 120 EP-513 (North Thin-ply Technology), K50 (SK chemicals) and 913 (Hexcel), all having a $120^{\circ} \mathrm{C}$ recommended cure temperature by the suppliers. The resins were found to be compatible, although no details were provided by the 
suppliers on their chemical formulations. Good integrity of the hybrid laminates was confirmed during test procedures and no phase separation was observed on cross sectional micrographs. Fabrication of the specimens was done using a diamond cutting wheel. As shown in Figure 4, two different types of $3 \mathrm{~mm}$ nominal size notches were manufactured in the fabricated specimens. The open-hole sample was fabricated with a diamond drill on a CNC milling machine and the sharp notched sample was fabricated in two steps: (1) drilling of a $2 \mathrm{~mm}$ long slot with a $1 \mathrm{~mm}$ diameter drill and (2) manual cutting of the rest of the nominal notch width symmetrically with a $180 \mu \mathrm{m}$ wide diamond wire saw. End tabs made of $2 \mathrm{~mm}$ thick woven glass/epoxy plates supplied by Heathcotes Co. Ltd. were bonded to the specimens using a two component Araldite 2000 A/B epoxy adhesive supplied by Huntsman; the components were mixed with the volume fraction ratio of 100: 50 for A: B respectively and cured for 120 minutes at $80{ }^{\circ} \mathrm{C}$ inside a Carbolite oven.

\subsection{Test procedure}

Tensile testing of the un-notched, open-hole and sharp notched laminates was performed under uniaxial loading with displacement control using a crosshead speed of $1 \mathrm{~mm} / \mathrm{min}$ for the unnotched laminates and $0.5 \mathrm{~mm} / \mathrm{min}$ for the open-hole and sharp notched laminates, on a computer controlled Instron 8801 type $100 \mathrm{kN}$ rated universal hydraulic test machine with wedge-type hydraulic grips. The reason for the different loading rates was to get similar strain rates for the different length specimens. The reason for a shorter length for the notched and open-hole samples, compared with the un-notched samples, was to make more samples from the fabricated plates, therefore saving the raw materials and manufacturing cost. A $25 \mathrm{kN}$ load cell was used for better resolution in the expected load range. Details of the prepared specimen types and their nominal geometric parameters can be seen in Fig. 4. 


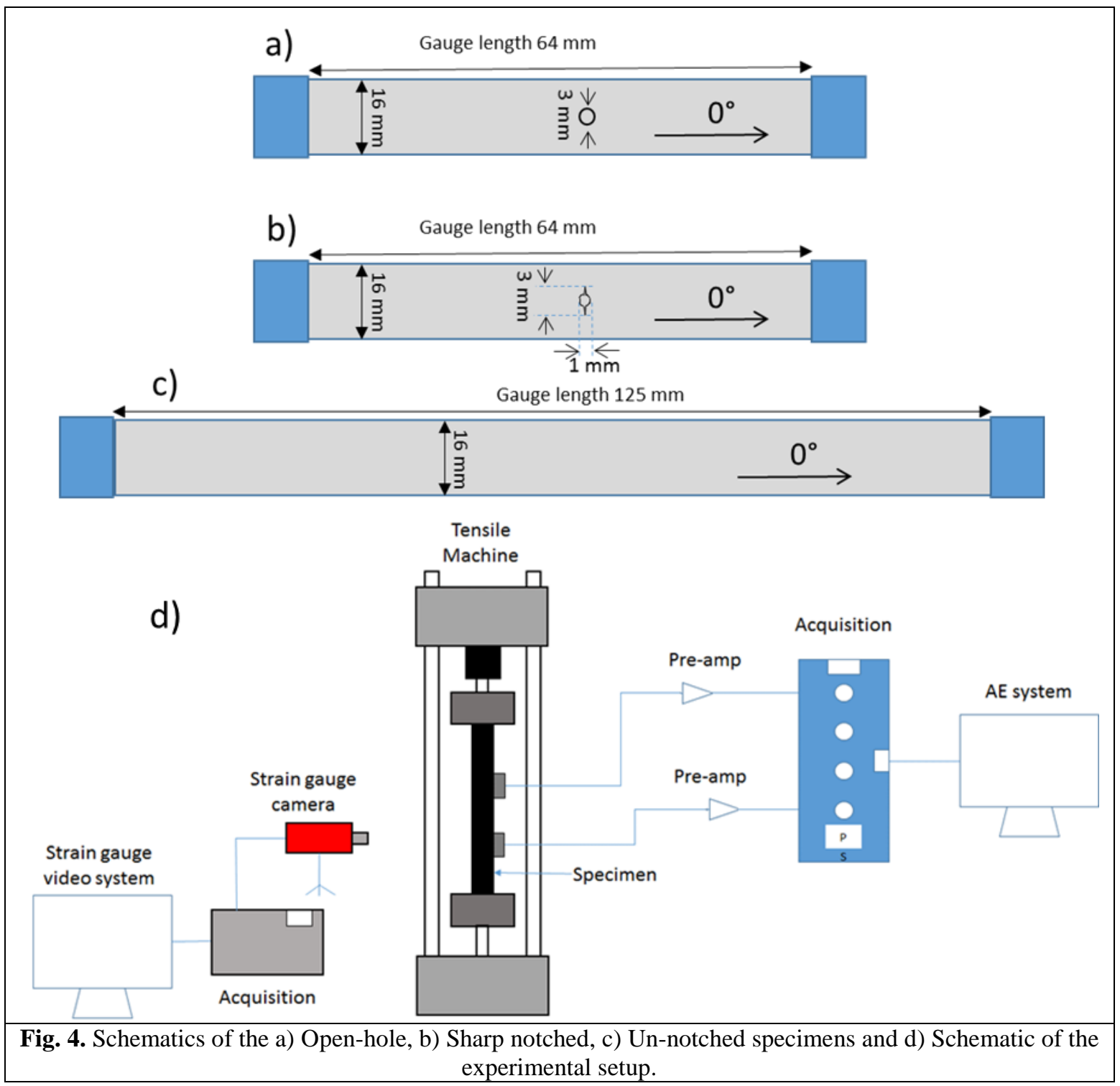

At least 6 specimens of each type were tested. To measure the strains an Imetrum video gauge system was used by tracking dotted patterns applied on the specimen faces.

\subsection{AE device}

An Acoustic Emission (AE) data acquisition system (PAC) PCI-2 with a maximum sampling rate of $40 \mathrm{MHz}$ was used to record the AE signals for the notched and open-hole configurations. PAC R15 resonant-type, broadband, single-crystal piezoelectric transducers were used as the AE sensors. The frequency range of the sensors was $100-900 \mathrm{kHz}$ and the gain selector of the preamplifier was set to $40 \mathrm{~dB}$. Two AE sensors were located at a distance of $50 \mathrm{~mm}$ apart in 
the middle of the back side of the specimen, to monitor the damage events. The surface of the sensor was covered with silicone grease to provide good acoustic coupling between the specimen and the sensor. The test sampling rate and the threshold were $5 \mathrm{MHz}$ and $60 \mathrm{~dB}$, respectively. A pencil lead break procedure was used to calibrate the data acquisition system for each of the specimens. After the calibration step, the AE signals were recorded during the tests and the features of the AE signals such as duration, rise time, amplitude, energy and count were extracted.

\section{Results and discussion}

\subsection{Un-notched results}

The stress-strain results for the investigated un-notched configurations are shown in Figs. 5-7. Table 3 summarizes some calculated values of the hybrid configurations. Due to the higher stiffness of the carbon layers in the North laminates, a higher improvement in the initial modulus is observable compared to the Hexcel laminate. The pseudo-yield strain values were higher $(1.03 \%)$ for the AP-North laminates compared to the QI-North laminates (0.92\%). This considerable rise (12\%), is believed to be the result of the so called hybrid effect, due to the stiffer adjacent $\pm 30^{\circ}$ plies in the AP-North laminates, compared to the $\pm 60^{\circ}$ plies in the QINorth laminates, as explained in more detail in our previous study [31]. Another factor that could cause a difference between the two layups is different thermal residual stresses. An analysis has therefore been done, utilising the properties listed in Table 1, to assess the potential effect of thermal residual stresses. The residual elastic strains in the $0^{\circ} \mathrm{M} 46 \mathrm{JB}$ layer are equal to $-0.08 \%$ for the QI-North and $+0.02 \%$ for the AP-North laminate. To account for the residual strains, pseudo-yield strain values in Table 3 should be summed with the calculated residual strain values. This will lead to an even a bigger difference: the pseudo-yield strain of the QINorth will be $0.92 \%+(-0.08 \%)=0.84 \%$ whereas for the AP-North, this value will be equal to $1.03 \%+0.02 \%=1.05 \%$, so residual stresses cannot explain the difference. 
In all the configurations, free edge delamination, an undesirable damage mode in previously investigated orientation-blocked hybrids [29], was successfully suppressed due to the orientation-dispersed design [30] that produces lower energy release rates at the free-edges of the laminates.

Fibre fracture in the carbon layers was the first observed failure mode for the investigated hybrid configurations. In order to provide a pseudo-ductile failure, the carbon layer fragmentations should be followed by stable pull-out to avoid instantaneous delamination. This is the case for the $\pm 30 \mathrm{AP} / \mathrm{North}(2), \pm 60 \mathrm{QI} /$ North (1) and $\pm 60 \mathrm{QI} / \mathrm{Hexcel}$ specimens, where the desired pseudo-ductile tensile stress-strain response with a linear initial part, a wide plateau and a second linear part was observed. These results agreed well with those expected according to the damage mode map predictions. Higher pseudo-ductile strain and a better load recovery after the plateau were obtained for the $\pm 60 \mathrm{Q} /$ Hexcel laminates compared with the North laminates. This is due to the lower relative carbon thickness and the better properties of the Sglass layers in the $\pm 60 \mathrm{QI} /$ Hexcel specimens compared with the North glass layers that had a lower strain to failure.

Table 3: Summary of the test results for the un-notched hybrid specimens.

\begin{tabular}{|c|c|c|c|c|c|c|c|c|c|}
\hline Specimen type & $\begin{array}{l}\text { Pseudo-yield } \\
\text { strain }(\%)\end{array}$ & $\begin{array}{l}\text { Pseudo- } \\
\text { yield } \\
\text { stress } \\
\text { (MPa) }\end{array}$ & $\begin{array}{c}\text { Final } \\
\text { failure } \\
\text { strain } \\
(\%)\end{array}$ & $\begin{array}{c}\text { Peso- } \\
\text { ductile } \\
\text { strain }(\%)\end{array}$ & $\begin{array}{l}\text { Final } \\
\text { failure } \\
\text { stress } \\
(\mathrm{MPa})\end{array}$ & $\begin{array}{c}\text { Initial } \\
\text { modulus } \\
(\mathrm{GPa})\end{array}$ & $\begin{array}{c}\text { Improvement } \\
\text { in modulus } \\
\text { compared to } \\
\text { the pure glass } \\
(\%)\end{array}$ & $\begin{array}{c}\text { Relative carbon } \\
\text { thickness }(\%)\end{array}$ & $\begin{array}{l}\text { Carbon block } \\
\text { thickness }(\mathrm{mm})\end{array}$ \\
\hline $\pm 30 \mathrm{AP} /$ North (1) & $1.03 \pm 0.05$ & $522 \pm 6$ & $1.14 \pm 0.09$ & $0.06 \pm 0.03$ & $527 \pm 20$ & $51.7 \pm 0.2$ & 61 & 22.5 & 0.174 \\
\hline $\pm 30 \mathrm{AP} /$ North (2) & $1.03 \pm 0.05$ & $530 \pm 6$ & $1.51 \pm 0.18$ & $0.33 \pm 0.25$ & $568 \pm 40$ & $51.7 \pm 0.2$ & 61 & 22.5 & 0.087 \\
\hline $\pm 60 \mathrm{QI} /$ North (1) & $0.92 \pm 0.05$ & $339 \pm 2$ & $1.95 \pm 0.14$ & $0.94 \pm 0.14$ & $378 \pm 18$ & $36.5 \pm 0.2$ & 54 & 22.5 & 0.174 \\
\hline $\pm 60 \mathrm{QI} /$ North (2) & $0.92 \pm 0.05$ & $328 \pm 4$ & $1.01 \pm 0.05$ & $0.08 \pm 0.03$ & $337 \pm 6$ & $36.5 \pm 0.2$ & 54 & 22.5 & 0.087 \\
\hline $\pm 60 \mathrm{Q} / / \mathrm{Hexcel}$ & $1.80 \pm 0.02$ & $379 \pm 6$ & $3.5 \pm 0.10$ & $1.30 \pm 0.05$ & $504 \pm 18$ & $25.1 \pm 0.1$ & 6 & 15.7 & 0.174 \\
\hline
\end{tabular}


Due to the high carbon thickness in the \pm 30 AP/North (1), after a few initial fragmentations across the carbon layers, there was a catastrophic delamination between the glass and carbon layers, as shown in Fig. 8. Whereas, in the $\pm 30 \mathrm{AP} /$ North (2), the lower carbon thickness prevents catastrophic delamination after the carbon layer fragmentations and results in a desired pseudo-ductile behaviour. There is a tiger stripe pattern of damage on the $\pm 30 \mathrm{AP} / \mathrm{North}$ (2) specimen due to the fragmentations and dispersed delaminations (see Fig. 9). The delaminated back surface of the glass layer blocks the visibility of the carbon. Therefore, in the tiger stripe pattern damage, the well bonded areas appear black, and the cracks in the carbon layer and the locally delaminated areas are light.

The experimental results show that the behaviour between configurations (1) and (2) are reversed for the $\pm 60 \mathrm{QI}-N$ orth compared with the AP-North laminates. This reverse behaviour is due to premature glass failure following fragmentation, and is consistent with the damage mode map predictions as indicated in Fig. 3. The \pm 60 QI-North (1) case is in the region with fragmentation but no delamination, and therefore the stress concentration on the adjacent plies is higher compared with the $\pm 60 \mathrm{QI}$-North (2) case which is in the fragmentation and delamination region. The different damage scenarios for the $\pm 60 \mathrm{QI}-$ North are displayed in Fig. 10. The damage modes in the $\pm 60 \mathrm{Q} /$ North (1) are consistent with the optimum damage scenario, where catastrophic delamination is avoided and fragmentation results in the desired pseudo-ductile behaviour. However, due to the low carbon thickness in the $\pm 60 \mathrm{QI} / \mathrm{North}(2)$, and consequently the low energy release rate, the stress concentration factor was higher. As a result, after limited localized fragmentations, there was a sudden failure in the glass layers. Although the carbon thickness in the $\pm 60 \mathrm{QI} /$ North (2) and the $\pm 30 \mathrm{AP} / \mathrm{North}(2)$ laminates is the same, there is a higher failure strain after the fragmentation in the $\pm 30 \mathrm{AP} / \mathrm{North}(2)$ laminate, due to the higher stiffness of the $\pm 30^{\circ}$ surrounding layers. The $\pm 60 \mathrm{QI} / \mathrm{North}(2)$ laminate has a premature failure as the remaining plies cannot carry the load after the initial 
fragmentation, whereas the $\pm 30 \mathrm{AP} /$ North (2) laminate can carry the load after fragmentation and also supress the catastrophic delamination and therefore results in a desired pseudo-ductile behaviour. More details of the effect of the stress concentration on final failure of the high strain plies can be found in [28].

The appearance of the $\pm 60 \mathrm{QI} / \mathrm{Hexcel}$ specimen is also illustrated in Fig. 11 and obvious carbon layer fragmentations and dispersed delaminations can be seen.

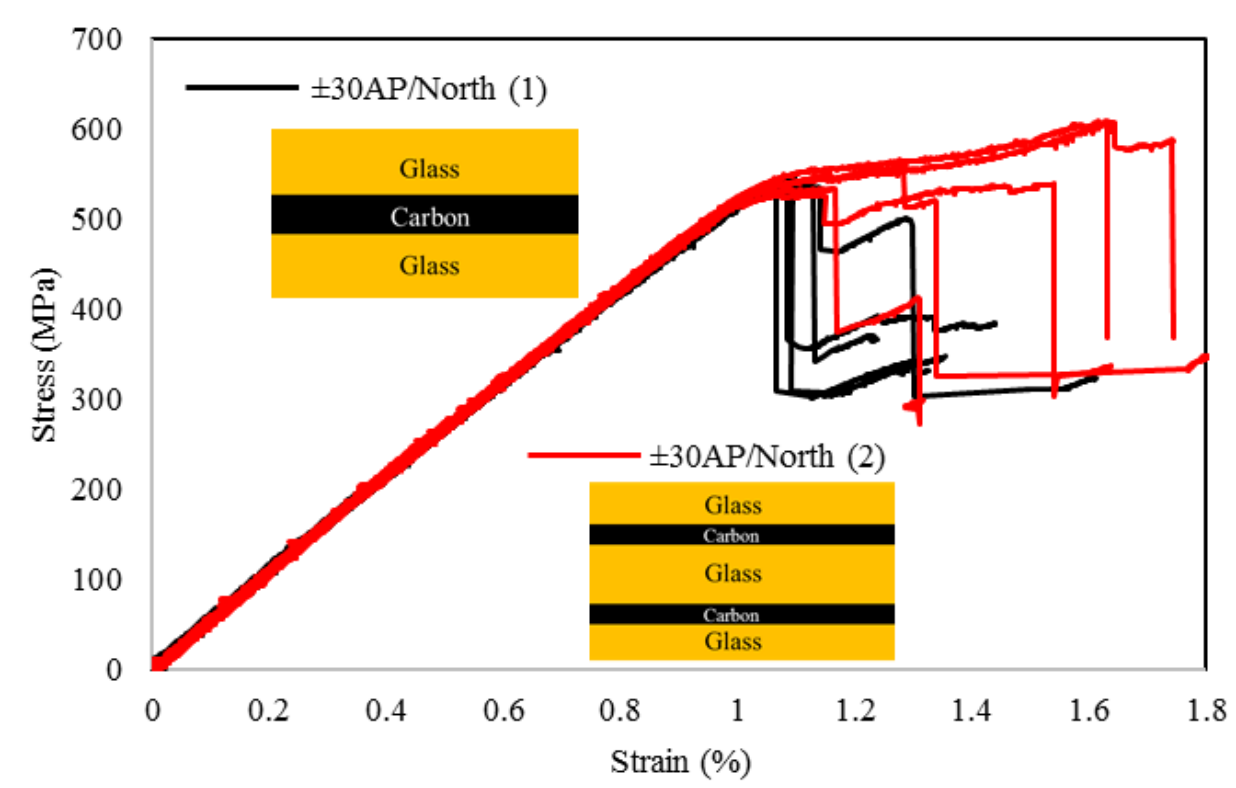

Fig. 5. Results of the tensile tests for the $\pm 30 \mathrm{AP} /$ North (1) \& $\pm 30 \mathrm{AP} /$ North (2). 


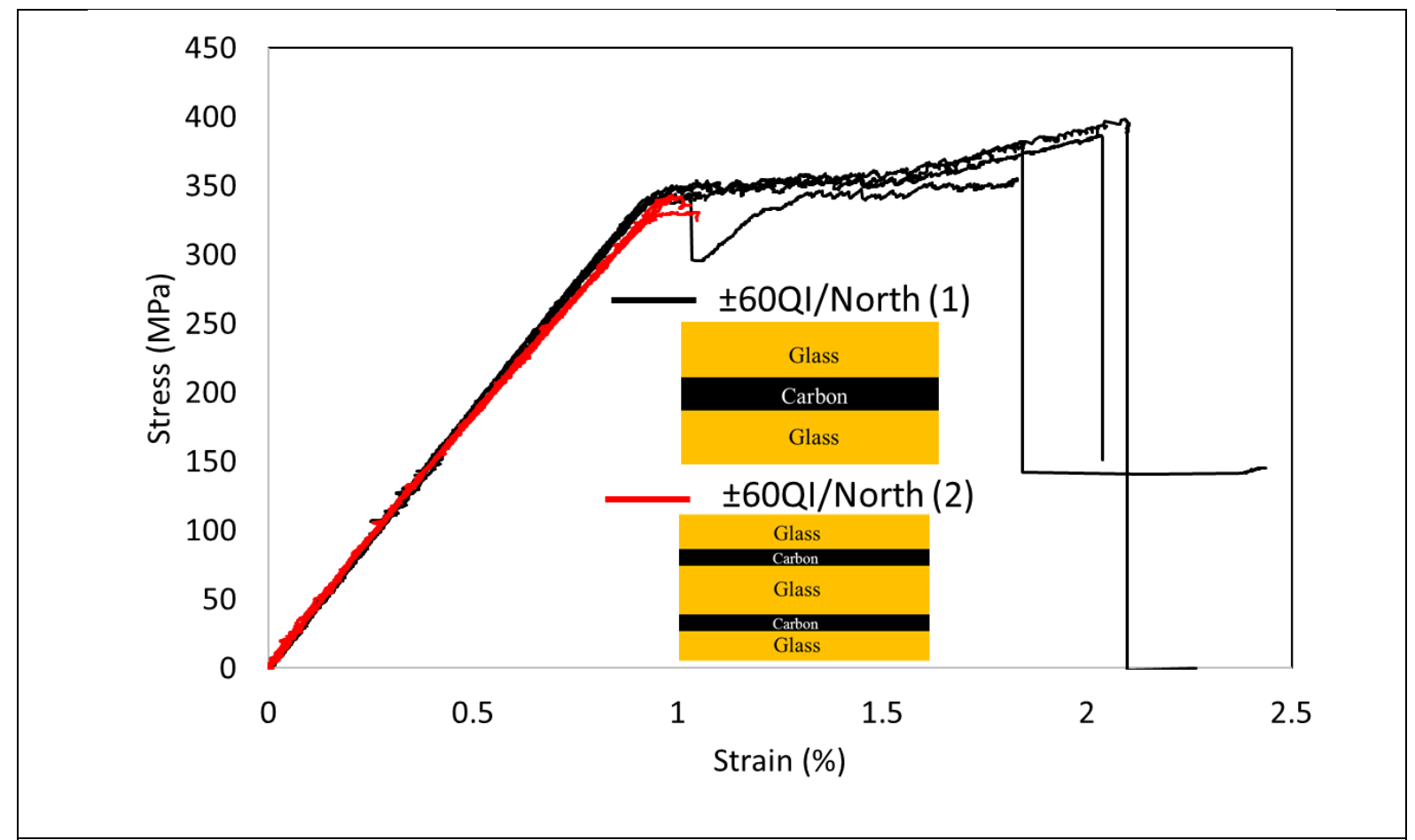

Fig. 6. Results of the tensile tests for the $\pm 60 \mathrm{QI} /$ North (1) \& $\pm 60 \mathrm{QI} /$ North (2).

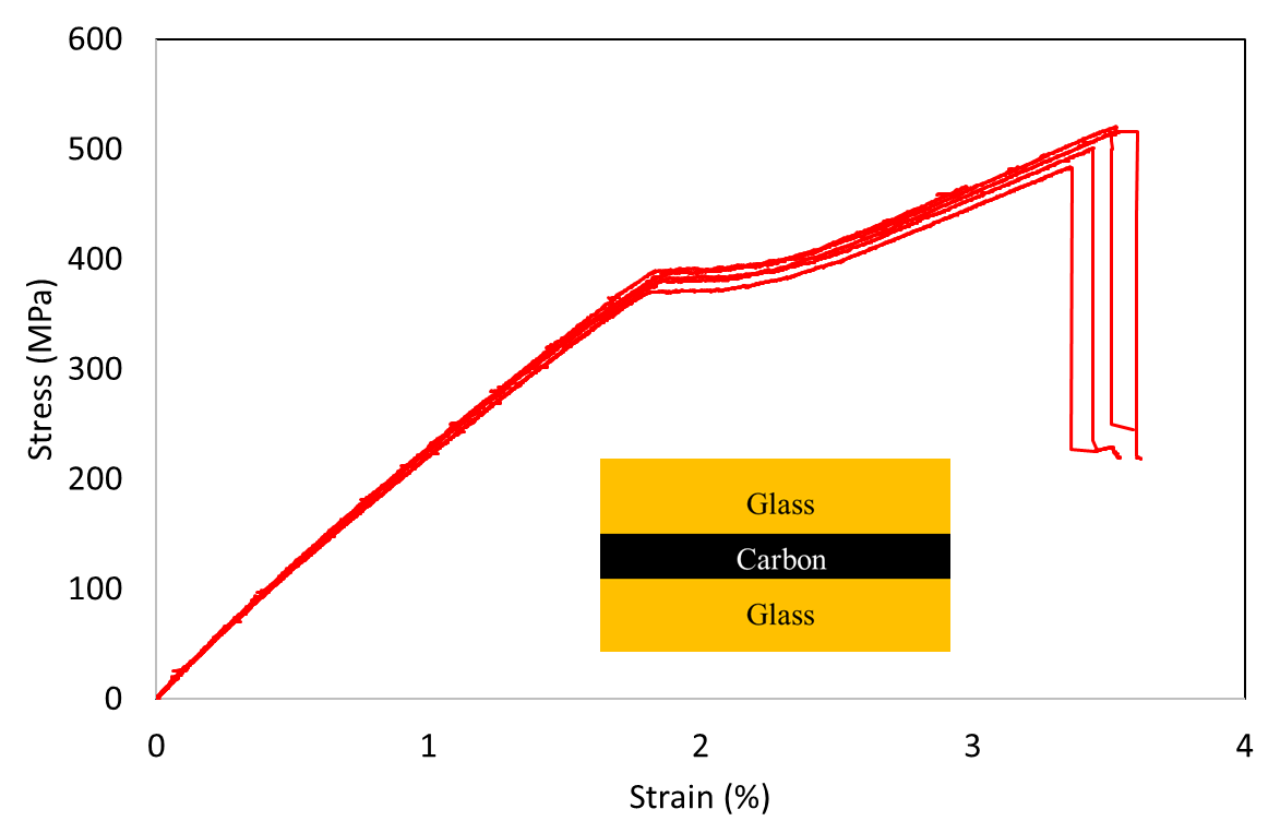

Fig. 7. Results of the tensile tests for the $\pm 60 \mathrm{QI} /$ Hexcel. 

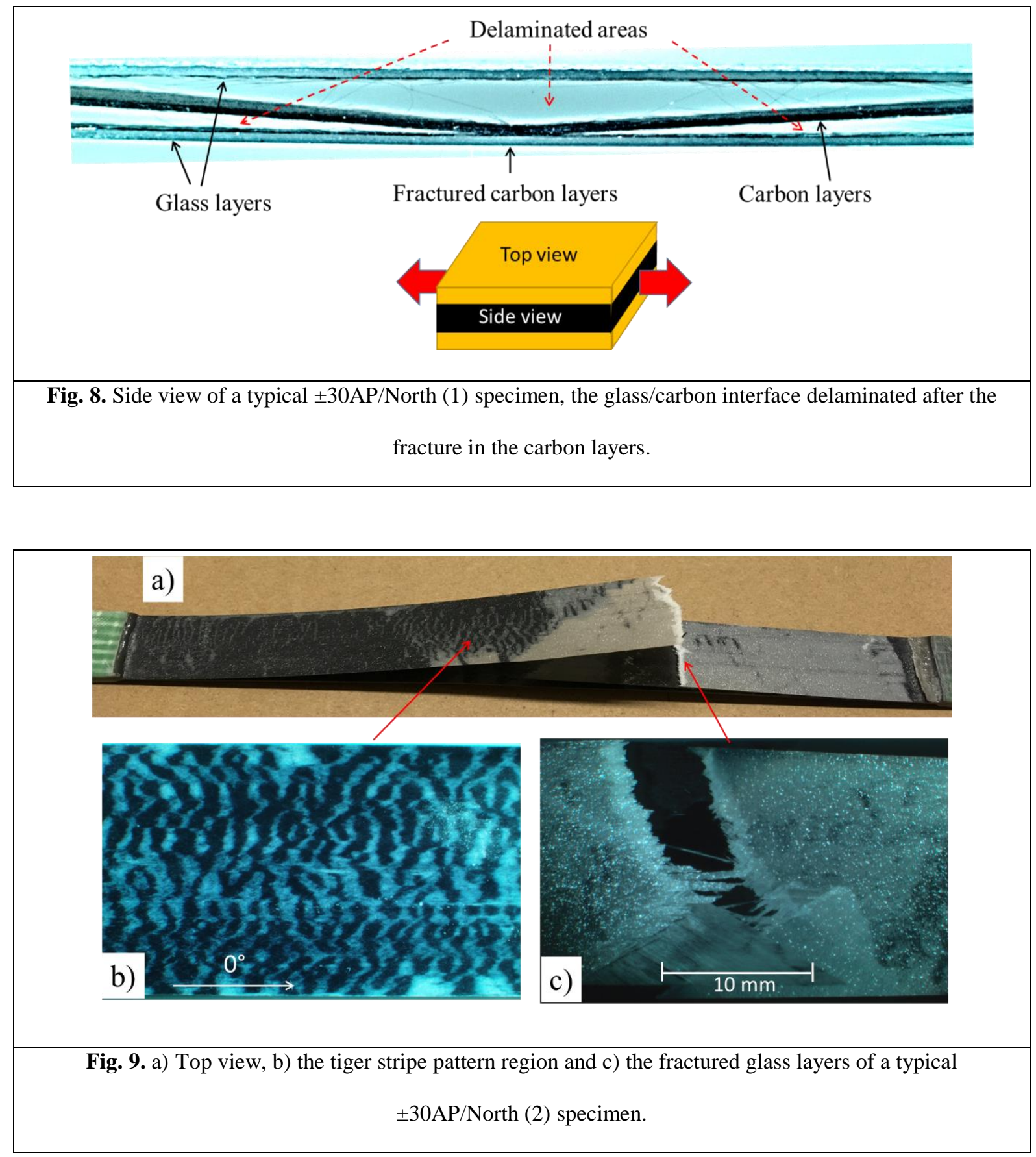

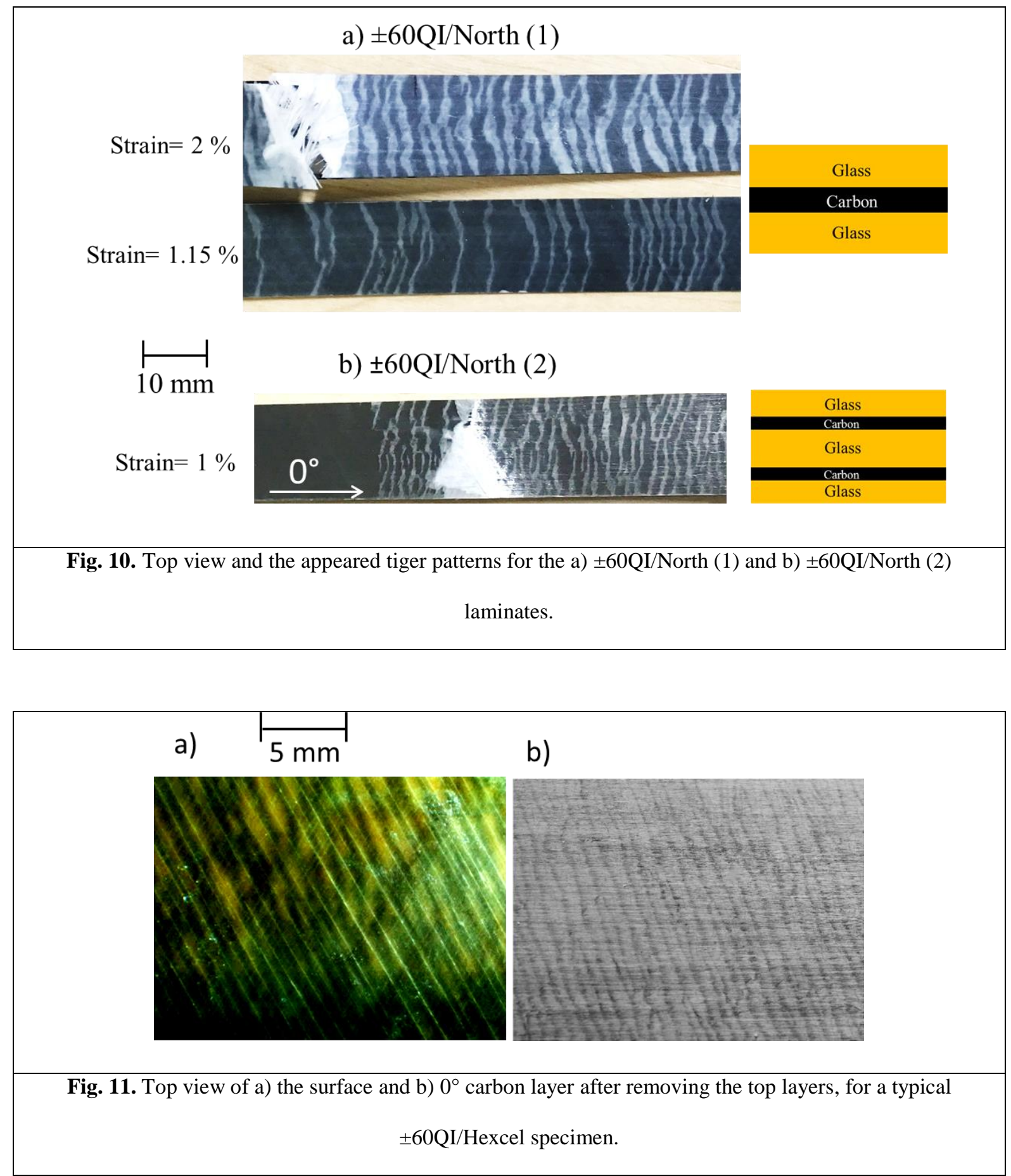

\subsection{Sharp notched and open-hole results}

As represented in Figs. 12-16, the introduced AP and QI hybrid laminates showed better performance and reduced notch sensitivity by redistributing stress. This is because of introducing new damage mechanisms, i.e. dispersed delamination and fragmentations, which developed around the notch tips, suppress the brittle failure and cause a pseudo-ductile 
behaviour. This behaviour is in contrast with conventional thin-ply laminates, where due to the damage suppression capability of the thinner plies and absence of subcritical damage such as transverse cracking or delamination, conventional thin-ply laminates exhibit a brittle netsection failure mode [20]. Similar to the un-notched configurations, no free edge delamination damage was observed for the notched laminates, showing the better performance of the orientation-dispersed concept compared to previously investigated orientation-blocked hybrids [29].

For an orthotropic composite plate with a central hole and with the same notch geometry as the investigated laminates, the elastic stress concentration factors for the AP and QI laminates are 3.43 and 3.13, respectively. These values are evaluated using Equations 1-3 [38-39], where $K_{t}^{\infty}, K_{t}, \mathrm{E} 1, \mathrm{E} 2, \mathrm{G} 12, \vartheta 12$, a and $\mathrm{W}$ are stress concentrations for infinite and finite width, elastic moduli in the fibre and transverse directions, in-plane shear modulus, Poisson ratio, hole diameter and specimen width, respectively.

\begin{tabular}{|l|l|}
\hline$K_{t}^{\infty}=1+\sqrt{2 \sqrt{\frac{E 1}{E 2}}-2 \vartheta 12+\frac{E 1}{G 12}}$ & Equation 1 \\
\hline
\end{tabular}

$$
\frac{K_{t}^{\infty}}{K_{t}}=\frac{3\left(1-\frac{a}{W}\right)}{2+\left(1-\frac{a}{W}\right)^{3}}+\frac{1}{2}\left(\frac{a}{W} M\right)^{6}\left(K_{t}^{\infty}-3\right)\left(1-\left(\frac{a}{W} M\right)^{2}\right)
$$

Equation 2

$$
M^{2}=\frac{\sqrt{1-8\left[\frac{3\left(1-\frac{a}{W}\right)}{2+\left(1-\frac{a}{W}\right)^{3}}-1\right]}-1}{2\left(\frac{a}{W}\right)^{2}}
$$

Equation 3 
Table 4 shows the pseudo-yield strain, un-notched pseudo-ductile strain and a notch insensitivity factor (NIF) for the hybrid configurations. The NIF is defined as the net section failure stress for the notched laminate divided by the final failure stress for the un-notched laminate. A NIF value $\geq 1$ means that the net section strength of the laminate does not change due to the existence of the notch. In contrast, the NIF value $\sim 0.392$ indicates the highest possible reduction in the QI laminate strength caused by the presence of the notch. This value is calculated by considering the ratio of the net section stress level and the stress concentration level. As illustrated in Fig. 17, in an ideally brittle QI material with the notch geometry similar to the investigated laminates, if the applied stress is $1 \mathrm{MPa}$, the net section stress would be 1.23 MPa, i.e. $1^{*}(16 / 13)$, and the stress concentration at the hole is $3.13 \mathrm{MPa}$, so the NIF would be 0.392 (i.e. $1.23 / 3.13$ ).

The notch insensitive behavior in the investigated laminates is well-illustrated by the notch sensitivity chart in Fig. 18. The notch insensitive line shows the situation in which the net section strength of the laminate does not change due to the existence of the notch. In contrast, the notch sensitive line shows the highest expected reduction in laminate strength caused by the presence of the notch. The evaluated experimental results lie very close to the notch insensitive line. For the laminates with lower values of pseudo-ductile strain, the notch insensitivity values are slightly higher for the sharp notched compared with the open-hole. A similar trend is seen in conventional quasi-isotropic IM7/8552 composite laminates where due to splitting centre-notched samples showed higher average tensile failure stress compared to the open-hole samples [40]. However, the laminates with a higher pseudo-ductile strain give slightly higher average tensile failure stress in the open-hole configuration compared with the sharp notched configuration. Further consideration is needed to understand this different behavior. 


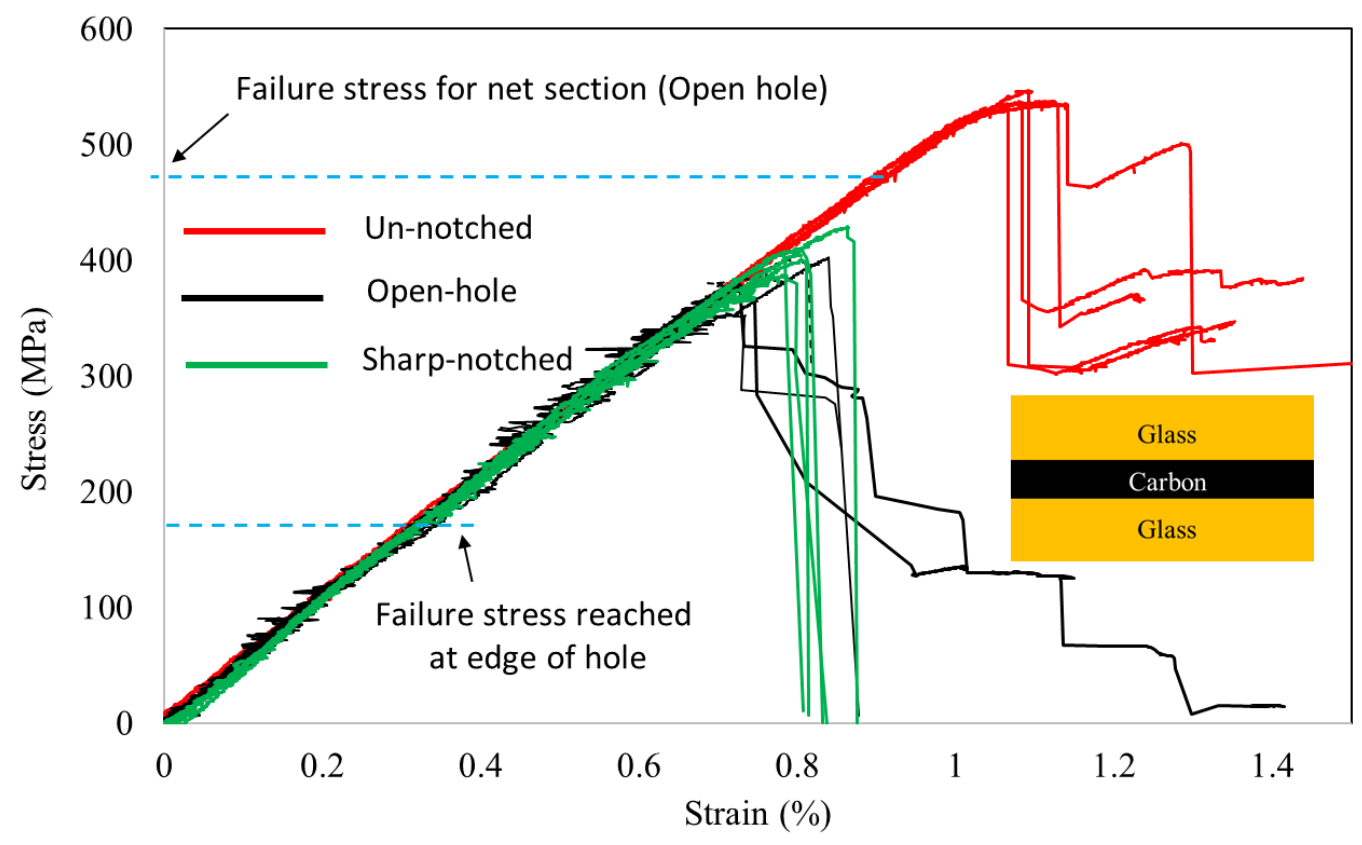

Fig. 12. Results of the tensile tests for the un-notched, sharp notched and open-hole \pm 30 AP/North (1) laminates.

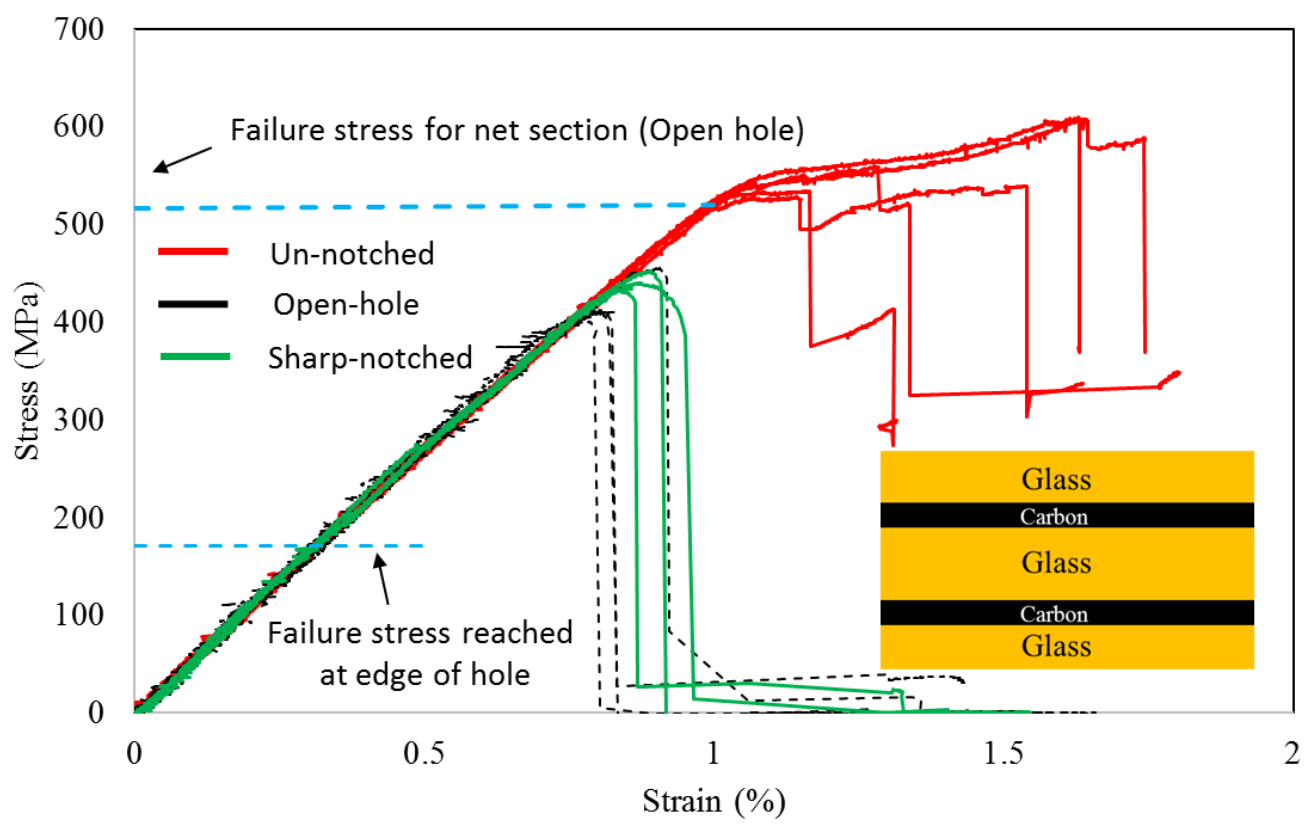

Fig. 13. Results of the tensile tests for the un-notched, sharp notched and open-hole $\pm 30 \mathrm{AP} /$ North (2) laminates. 

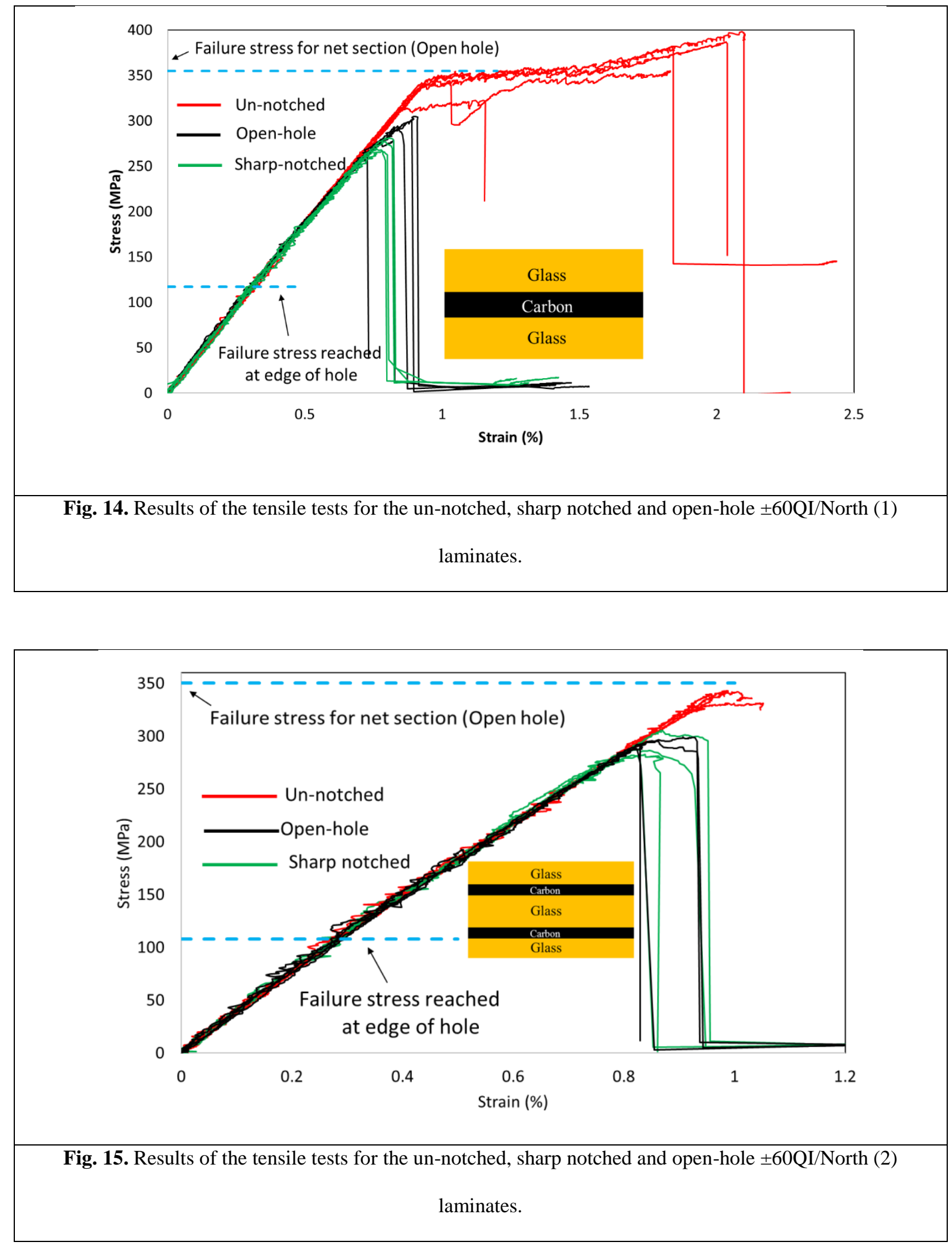


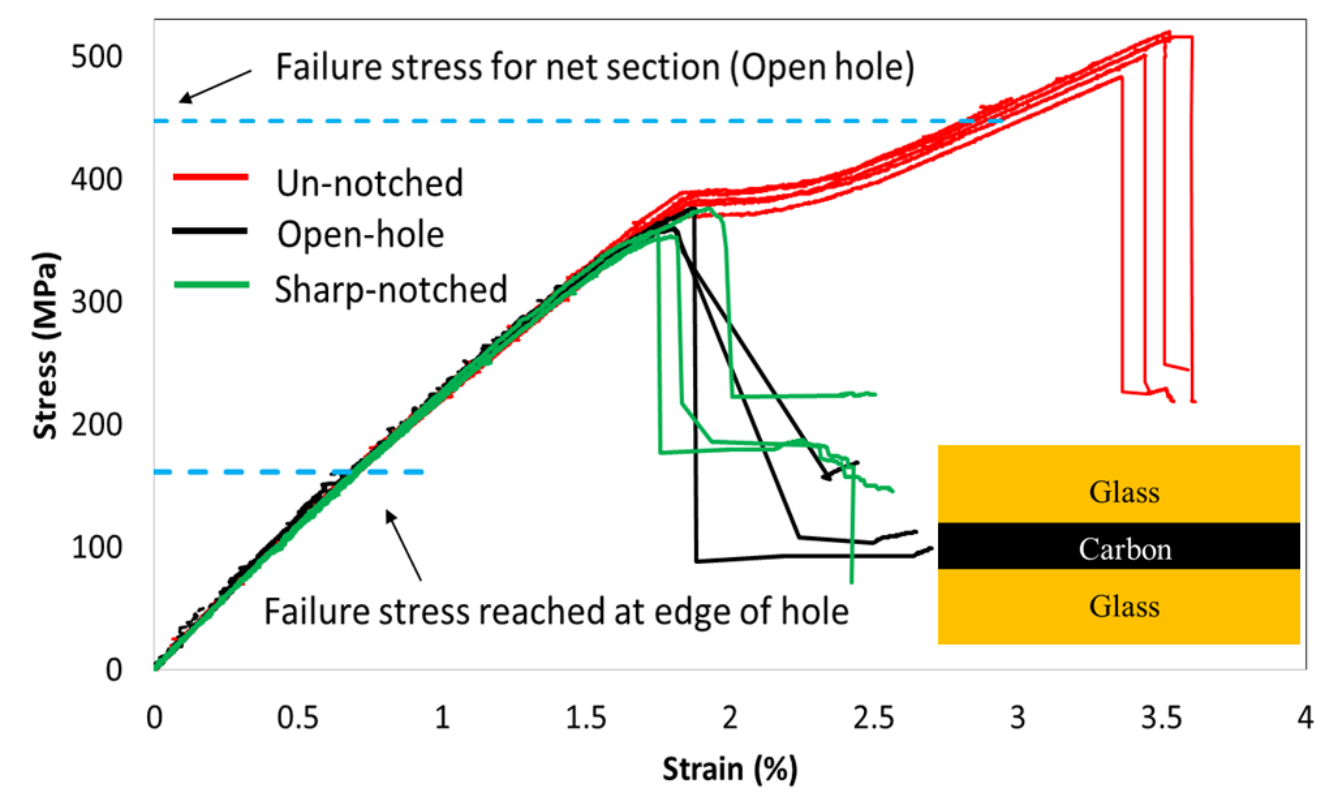

Fig. 16. Results of the tensile tests for the un-notched, sharp notched and open-hole $\pm 60 \mathrm{QI} / \mathrm{Hexcel}$ laminates.

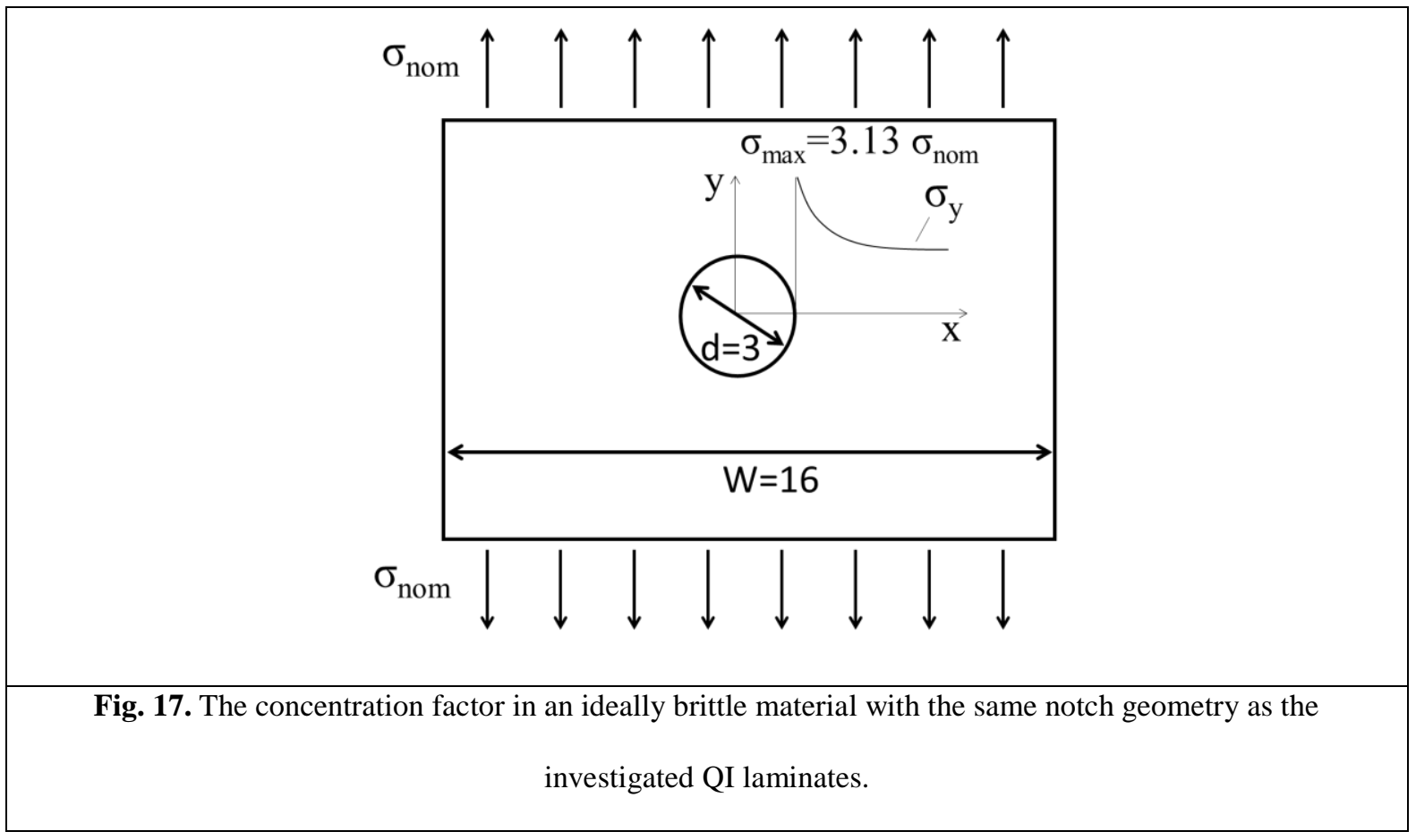

Table 4: Summary of the test results for the un-notched, open-hole and sharp notched hybrid specimens.

\begin{tabular}{|c|c|c|c|c|c|c|c|}
\hline Specimen type & $\begin{array}{c}\text { Un- } \\
\text { notched, } \\
\text { pseudo- } \\
\text { ductile } \\
\text { strain } \\
(\%)\end{array}$ & $\begin{array}{l}\text { Un-notched, } \\
\text { final failure } \\
\text { stress (MPa) }\end{array}$ & $\begin{array}{c}\text { Initial } \\
\text { modulu } \\
\mathrm{s}(\mathrm{GPa})\end{array}$ & $\begin{array}{c}\text { Failure } \\
\text { stress for net } \\
\text { section } \\
(\mathrm{MPa}) \\
\text { (Open-hole) }\end{array}$ & $\begin{array}{c}\text { Failure- } \\
\text { stress for net } \\
\text { section } \\
(\mathrm{MPa}) \\
\text { (Sharp } \\
\text { notched) }\end{array}$ & $\begin{array}{l}\text { NIF value } \\
\text { (Open- } \\
\text { hole) }\end{array}$ & $\begin{array}{c}\text { NIF value } \\
\text { (Sharp } \\
\text { notched) }\end{array}$ \\
\hline
\end{tabular}




\begin{tabular}{|c|c|c|c|c|c|c|c|}
\hline $\pm 30 \mathrm{AP} /$ North (1) & $0.06 \pm 0.03$ & $527 \pm 20$ & $51.7 \pm 0.4$ & $467 \pm 25$ & $520 \pm 20$ & 0.88 & 0.98 \\
\hline $\pm 30 \mathrm{AP} /$ North (2) & $0.33 \pm 0.25$ & $568 \pm 40$ & $51.7 \pm 0.4$ & $516 \pm 35$ & $541 \pm 12$ & 0.91 & 0.95 \\
\hline $\pm 60 \mathrm{QI} /$ North (1) & $0.94 \pm 0.14$ & $378 \pm 18$ & $36.5 \pm 0.5$ & $355 \pm 15$ & $329 \pm 7$ & 0.94 & 0.87 \\
\hline $\pm 60 \mathrm{QI} /$ North (2) & $0.08 \pm 0.03$ & $337 \pm 6$ & $36.5 \pm 0.5$ & $350 \pm 13$ & $355 \pm 6$ & 1.04 & 1.05 \\
\hline $\pm 60 \mathrm{Q} /$ Hexcel & $1.30 \pm 0.05$ & $504 \pm 18$ & $25.1 \pm 0.1$ & $447 \pm 6$ & $436 \pm 15$ & 0.88 & 0.86 \\
\hline
\end{tabular}

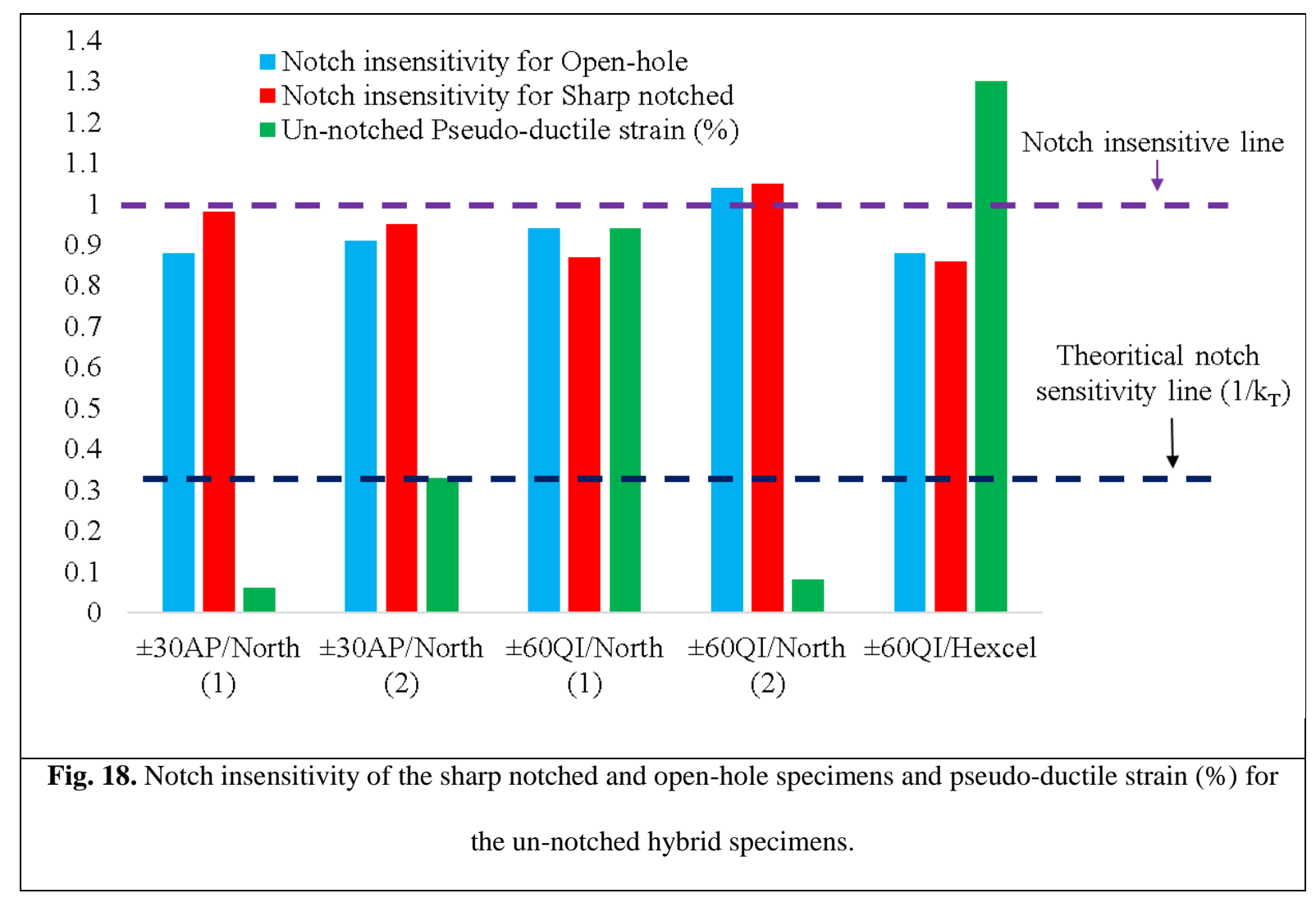

\subsection{Visual and CT-scan observations for the open-hole and notched samples}

Figs. 19-21 show some images and CT-scan observations taken from the sharp notched and open-hole configurations of $\pm 30 \mathrm{AP} /$ North (1) and $\pm 30 \mathrm{AP} / \mathrm{North}(2)$ at strain levels lower than the final failure. A short summary of the visual and CT-scan observations for the other investigated open-hole and sharp notched specimens can be found in the Appendix. All the investigated open-hole and sharp notched laminates exhibited subcritical failure mechanisms, i.e. dispersed delamination and fragmentations, as discussed below, which suppressed the brittle failure and decreased the notch sensitivity. The CT-scan images show that the damage initiates with obvious cracks in the carbon layers at the edge of the notch. These subcritical 
cracks were followed by dispersed delaminations at the glass/carbon interfaces. More details on the damage evolution can be found in the Appendix.

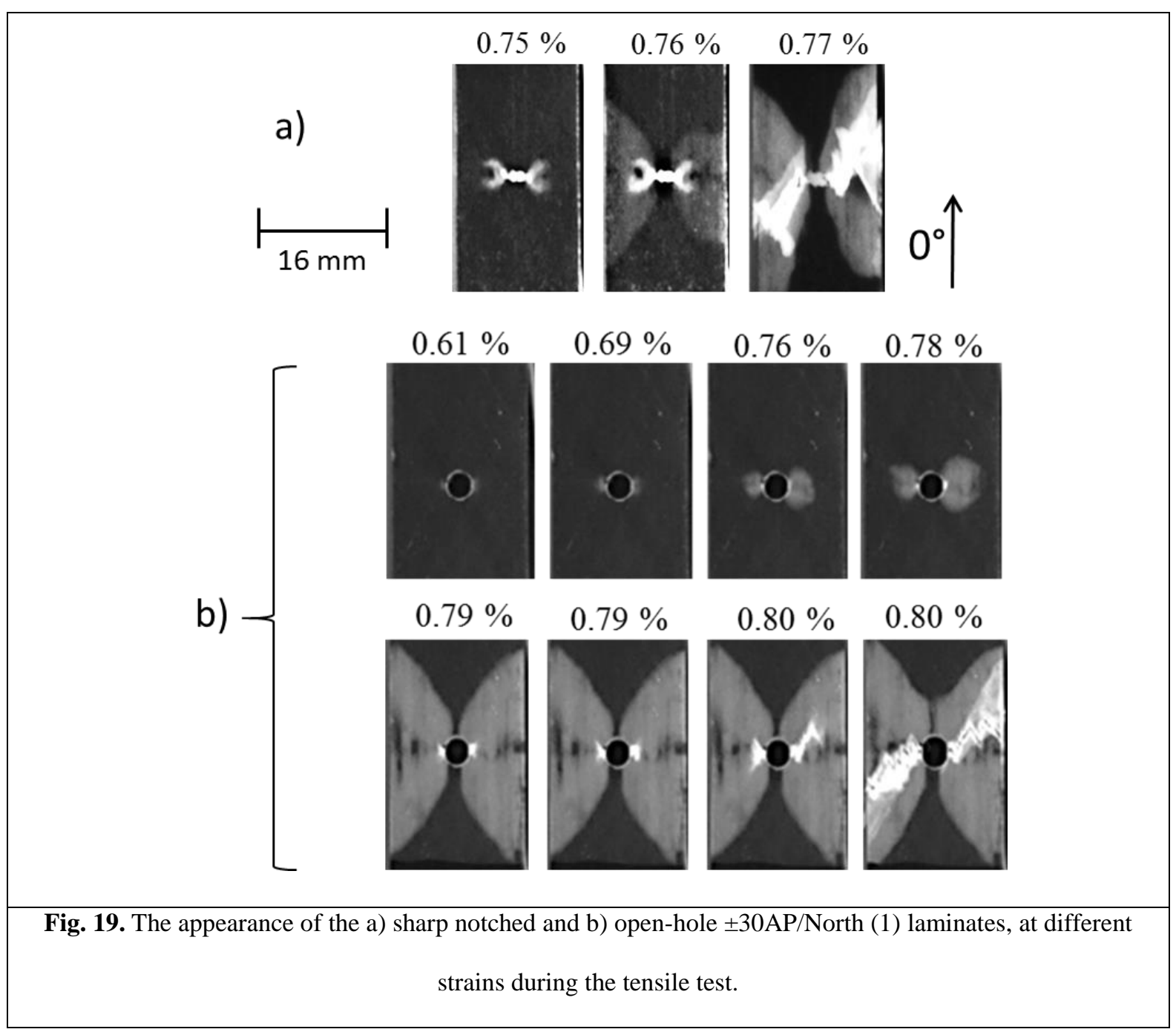



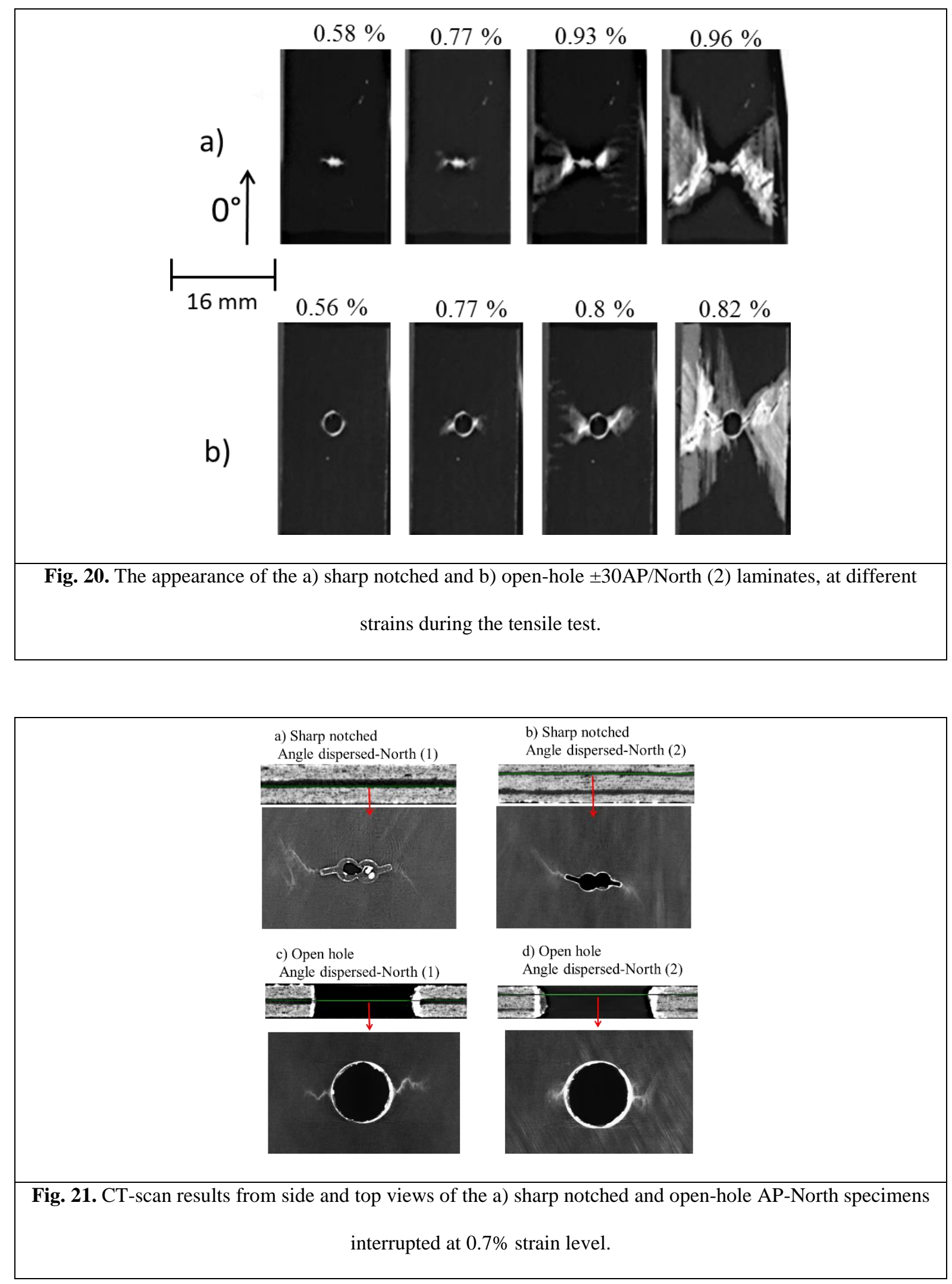

\subsection{AE results}


The accumulation of damage was also monitored using the AE technique in a few specimens of each configuration to confirm that the subcritical damage mechanisms happen much earlier than the final failure for the open-hole and sharp notched hybrid configurations. Previous studies in laminated composites reported that high amplitude and energy signals represent fibre fractures while medium values mostly correspond to delamination and interfacial debonding [41-42]. Based on the study on glass/carbon hybrid laminates [43-44], it was found that the carbon/glass interface delamination and fragmentation of the carbon plies occurred between 65-85 and 75-100 dB amplitude, respectively. Since that work was related to a similar type of thin-ply laminate, the same concept can be used to analyse the AE results.

Figs. 22 and 23 show typical plots of the acoustic amplitude for the different hybrid configurations. Significant high amplitude signals due to delamination and fragmentations were observed much earlier than the final failure.

The vertical dashed lines show the onset of significant damage, i.e. fragmentation and delamination, estimated from the appearance of the dense pattern of high amplitude AE signals, at 75-100 dB amplitude, based on the same criteria used in [43-44]. This demonstrates that there was active damage at the strain level close to that estimated from the theoretical stress concentration factor $\left(\sigma_{\mathrm{nom}} / \sigma_{\mathrm{max}}=3.13\right)$. These strain levels are much lower than the strain levels at which damage was visually observed on the specimens (see Figs. 19 ,20, 24, 26 and 28) showing the ability of the AE technique to detect early damage. The amplitude range of the AE signals are associated with the carbon/glass interface delamination (65-85dB) and fragmentation of the carbon fibre (75-100 dB) [44]. CT scan observations (Figs. 21, 25, 27 and 29) showed that invisible damage events occur only locally at the notch vicinity and the dense pattern of high amplitude acoustic events confirms their existence before the final failure.

At the early stage of the loading process and before the vertical dashed lines, some weak AE events were detected which must have been related to some microscale damage around the 
edges of the sample e.g. single fibres coming off the edge and/or grip rubbing effects, so they are considered as noise signals [44]. Please note that not all the samples were monitored by AE and this method was utilised just for damage monitoring of the specimens presented in Figs. 28-29.

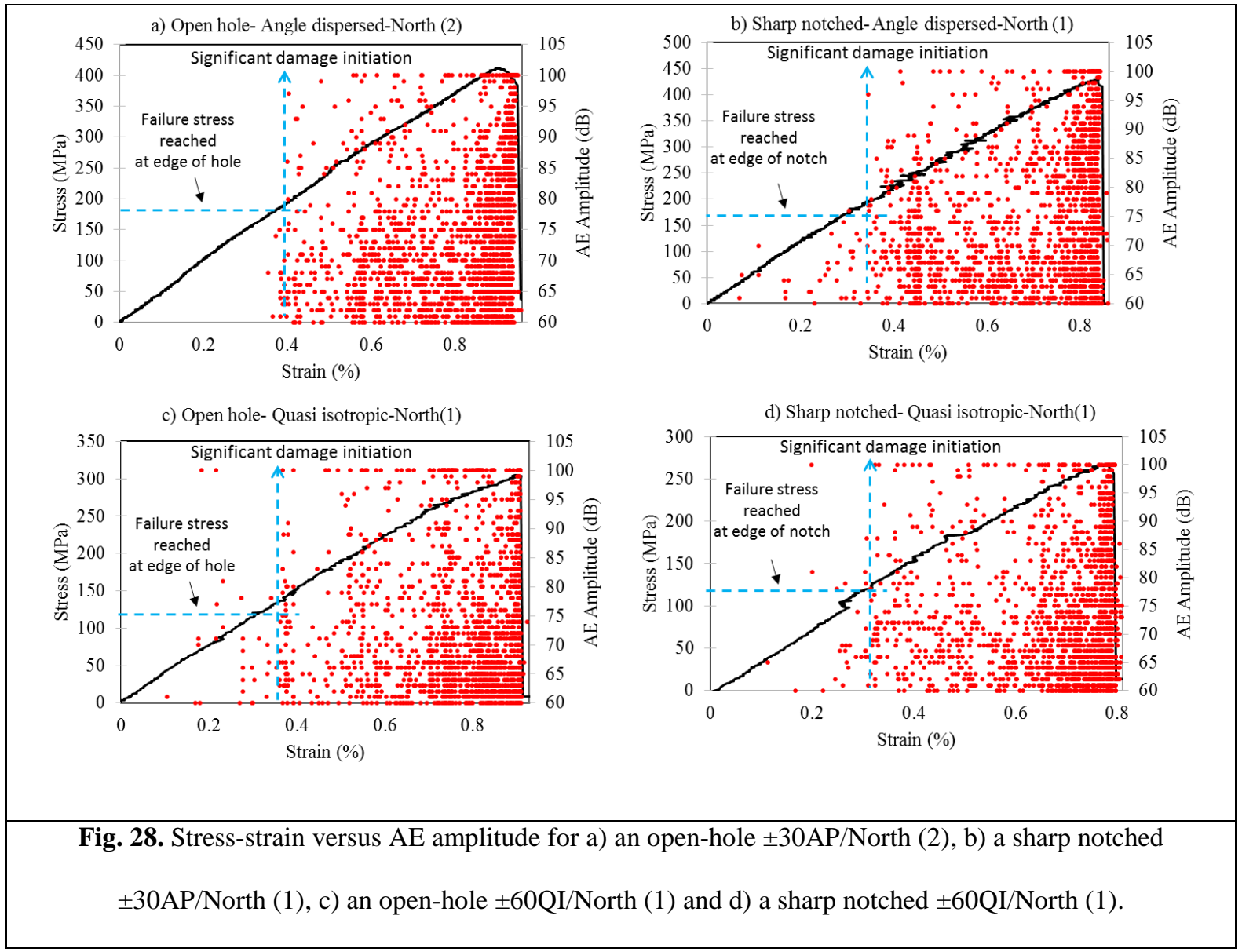




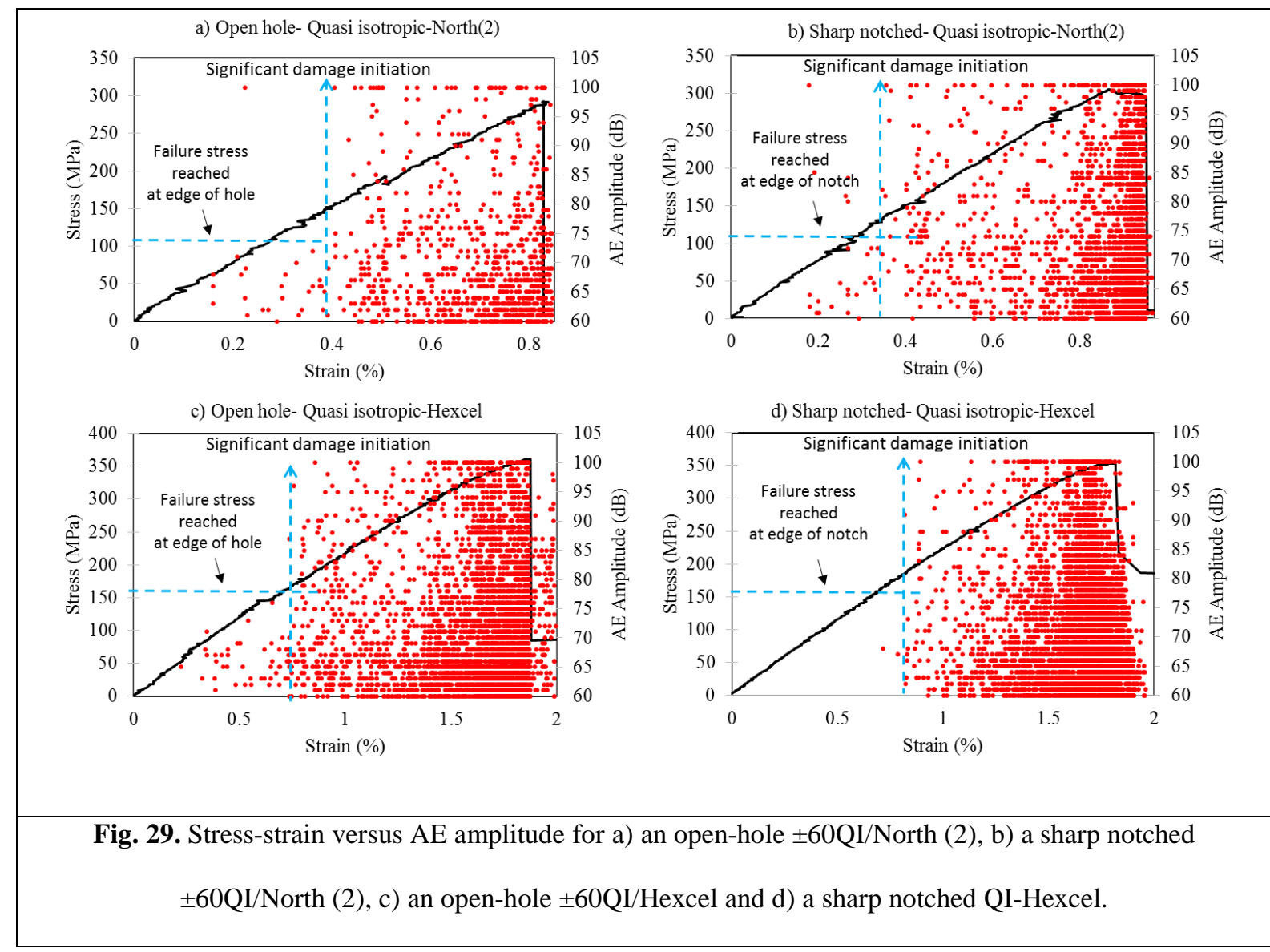

\section{Conclusions}

This study presents a comprehensive set of designed and characterised orientation-dispersed pseudo-ductile thin-ply glass/carbon hybrid composites to overcome some of the disadvantages related to the notched behavior and free edge delamination of conventional laminated composites. The following conclusions are drawn:

- Free edge delamination was successfully suppressed for both un-notched and notched configurations, showing the better performance of the orientation-dispersed concept compared to previously investigated orientation-blocked hybrids.

- A successful pseudo-ductile un-notched behaviour which also showed notchinsensitivity was achieved through subcritical pseudo-ductile damage mechanisms, i.e. dispersed delamination and fragmentations. 
- AE, visual and CT-scan observations showed that the dispersed delamination and fragmentations suppress the brittle failure by redistributing the stresses in the vicinity of the notch, and make a notch insensitive layup.

- The calculated notch insensitivity factors (NIF) for the open-hole specimens were close to the ideal value of 1 and they were far from the classical NIF in an ideally brittle QI material predicted by the notch geometry and elastic stress concentration factor (i.e. 0.392). This conclusion is also valid for the sharp notched specimens as they have a similar notch sensitivity as the open-hole laminates.

- By changing the ply angles, the relative thickness of the carbon layers and the material properties, different un-notched and notched behaviors were observed. For the specimens with a lower pseudo-ductile strain, the notch insensitivity values were slightly higher for the sharp notched compared with the open-hole specimens. However, the laminates with a higher pseudo-ductile strain give slightly better behavior in the open-hole configuration compared with the sharp notched configuration.

- Due to the translucent nature of the glass layers, the investigated hybrids have the advantage of allowing monitoring of the damage evolution with the naked eye. This can be very useful for inspection purposes, as the damage can be detected visually around the notches before any catastrophic failure.

\section{Acknowledgements}

This work was funded under the UK Engineering and Physical Sciences Research Council (EPSRC) Programme Grant EP/I02946X/1 on High Performance Ductile Composite Technology in collaboration with Imperial College, London. The authors acknowledge Hexcel Corporation for supplying materials for this research. The data necessary to support the conclusions are included in the paper. 


\section{Appendix: Visual and CT-scan observations for the open-hole and sharp notched samples}

Figs. 24-27 illustrate the visual and CT-scan observations for the investigated specimens. The investigated laminates exhibited subcritical failure mechanisms similar to the un-notched configurations, i.e. dispersed delamination and fragmentations, not seen in all cases, as discussed below which suppressed the brittle failure and decreased the notch sensitivity. The desired subcritical pseudo-ductile failure mechanisms were observed for all the investigated sharp notched and open-hole cases, even though there was an unfavourable catastrophic failure for the $\pm 30 \mathrm{AP} /$ North (1) and $\pm 60 \mathrm{QI} /$ North (2) laminates.

Figs. 21, 23, 25 and 27 show CT-scan images for the investigated specimens interrupted at strain levels lower than the final failure and as can be seen the damage initiates with obvious cracks in the carbon layers at the edge of the notch. These subcritical cracks were followed by dispersed delaminations at the glass/carbon interfaces. For the laminates with the low carbon thickness, i.e. $\pm 30 \mathrm{AP} /$ North (2) and $\pm 60 \mathrm{QI} /$ North (2), the initial crack occurs in all the carbon layers. However, comparing the CT-scans taken from different locations of the carbon layers in Figs. 23, 25 and 27, for the rest of the laminates with the high carbon thicknesses the size of the initial crack is larger for the carbon layers in the vicinity of the glass layers due to the stress concentration at the glass/carbon interfaces.

The observed subcritical failure mechanisms in the notched and open-hole configurations are similar to the previously investigated orientation-blocked low strain carbon/epoxy hybridised with high strain carbon/epoxy configurations, where local damage (i.e. local delamination induced by carbon layer fragmentation) next to the notches resulted in a notch insensitive behaviour. CT-scan observation was necessary to determine the damage scenario, as the hybrids were all carbon and it was not possible to see the damage evolution visually [29]. The investigated hybrids in this paper have the advantage of allowing monitoring of the damage evolution with the naked eye, due to the translucent nature of the glass layers. This can be an 
advantage for inspection purposes, where the damage can be detected visually around the notches before any catastrophic failure.
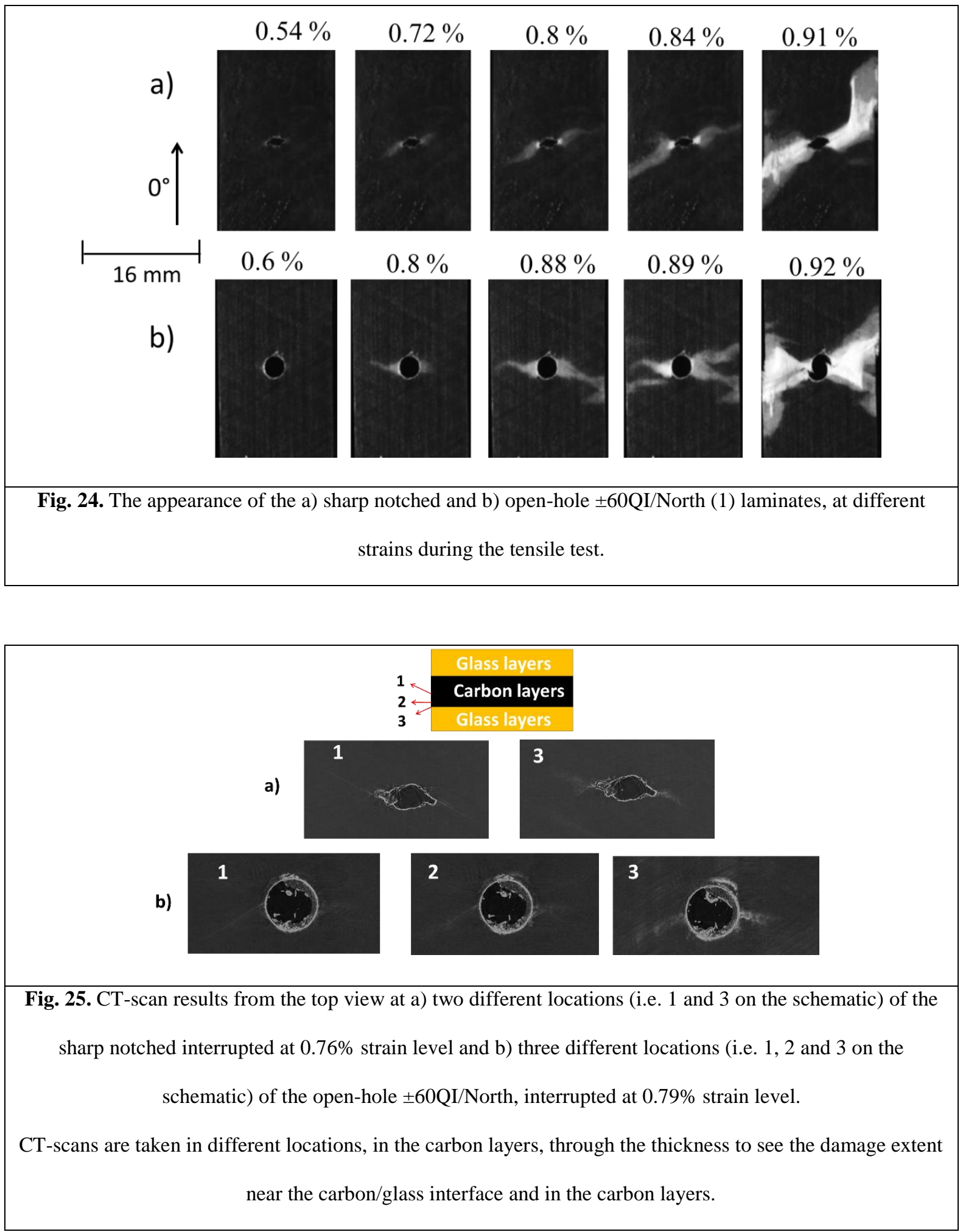

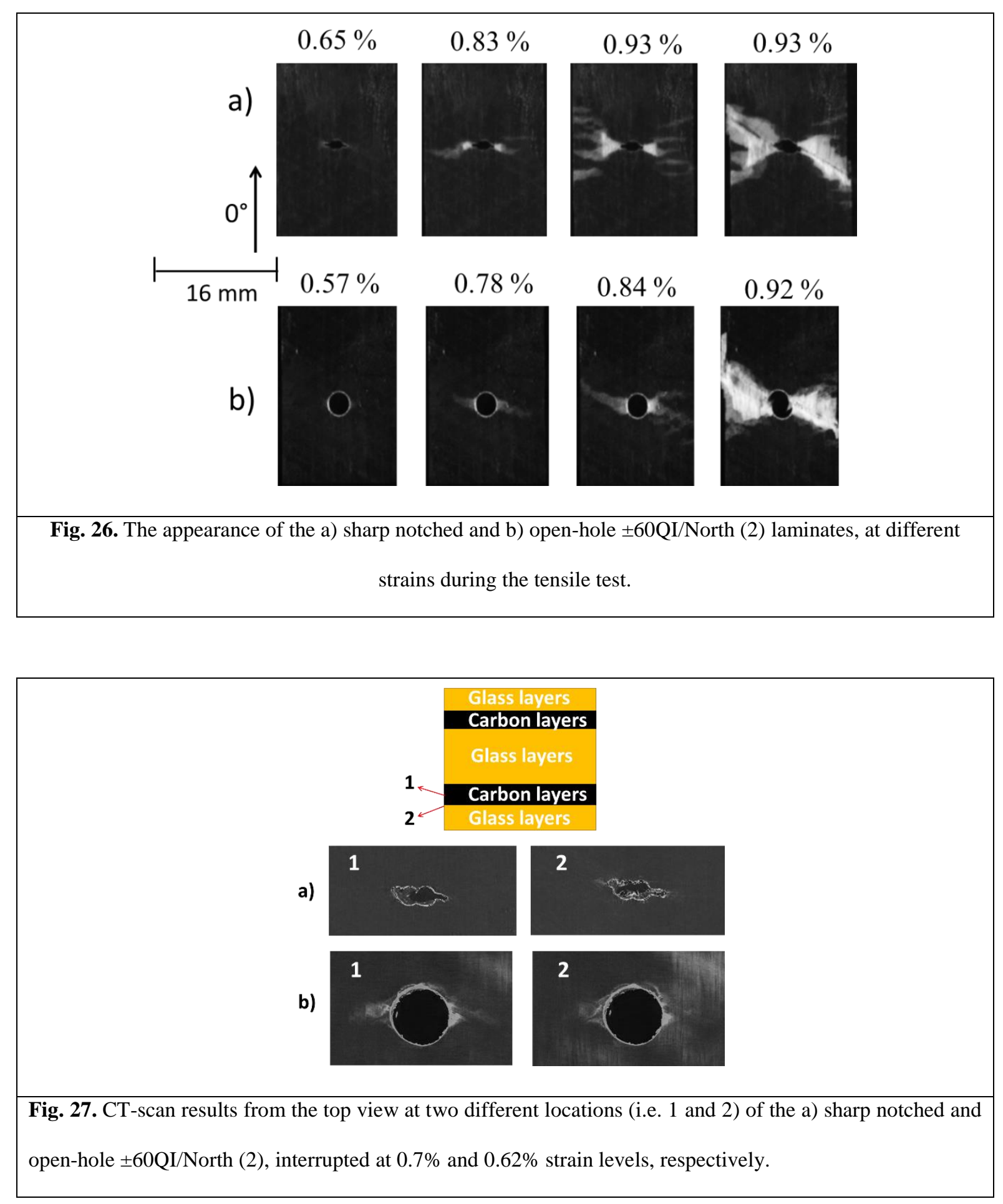

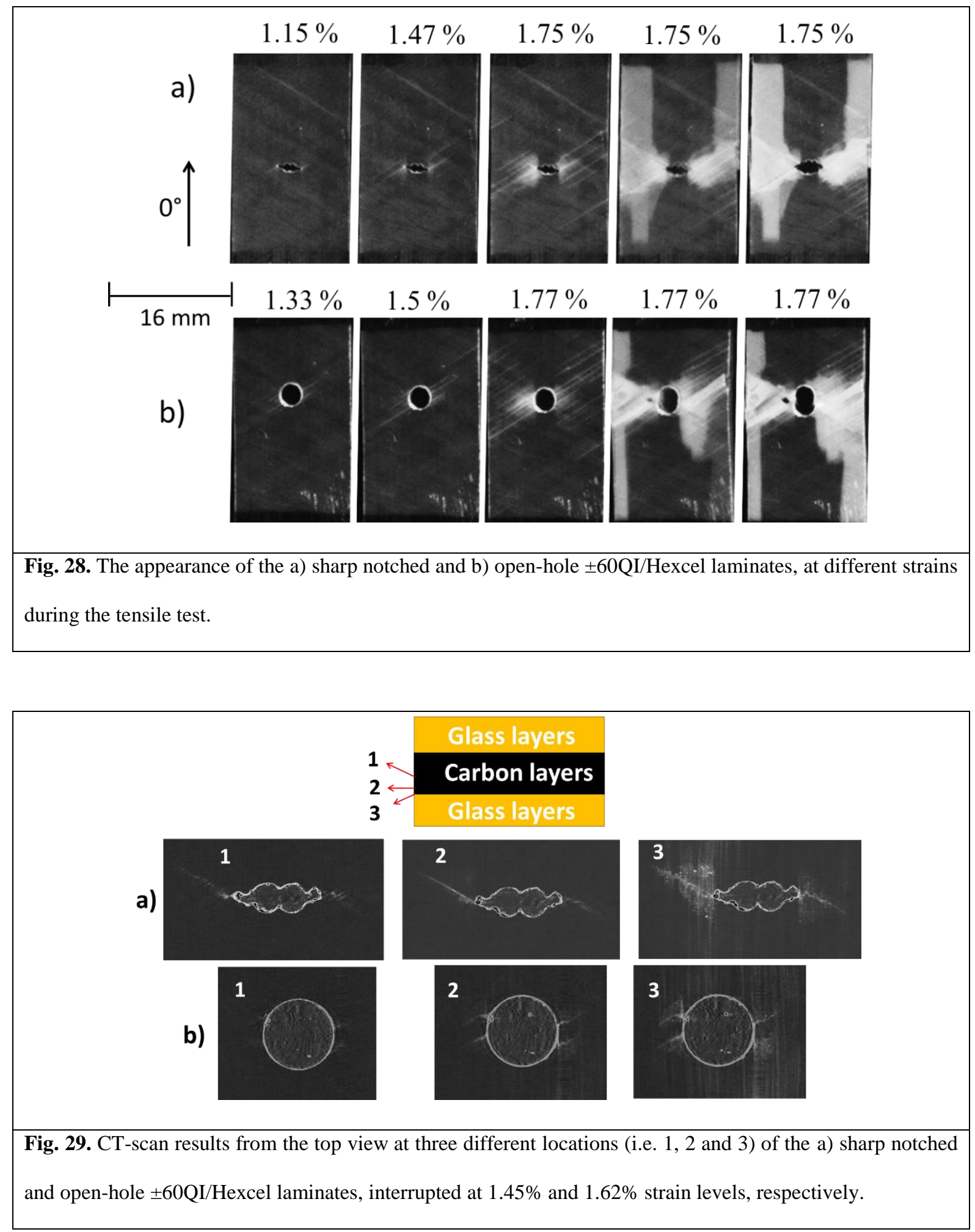

\section{References:}

[1] J Awerbuch, MS Madhukar. Notched strength of composite laminates: predictions and experiments - a review. J Reinf Plast Comp, 4:3-159, 1985.

[2] JM Whitney, RJ Nuismer. Stress fracture criteria for laminated composites containing stress concentrations. J Compos Mater 8:253-65, 1974. 
[3] Jr Poe CC, JA Sova. Fracture toughness of boron/ aluminium laminates with various proportions of 0 and \pm 45 plies. NASA Technical Paper 1707, 1980.

[4] SR Hallett, MR Wisnom. Experimental investigation of progressive damage and the effect of layup in notched tensile tests. J Compos Mater, 40:119-41, 2006.

[5] MR Wisnom, SR Hallett. The role of delamination in strength, failure mechanisms and hole size effect in open hole tensile tests on quasi-isotropic laminates. Compos Part A Appl S, 40:335-42, 2009.

[6] ME Waddoups, JR Eisenmann and BE Kaminski. Macroscopic fracture mechanics of advanced composite materials. Journal of Composite Materials, 5:446-454, 1971.

[7] JM Whitney and RJ Nuismer. Stress fracture criteria for laminated composites containing stress concentrations. Journal of Composite Materials, 8: 253-265, 1974.

[8] RB Pipes, RC Wetherhold and JW Gillespie Jr. Notched strength of composite materials. Journal of Composite Materials, 13:148-160, 1979.

[9] MT Kortschot and PWR Beaumont. Damage mechanics of composite materials: I - Measurements of damage and strength. Composites Science and Technology, 39:289-301, 1990.

[10] MT Kortschot and PWR Beaumont. Damage mechanics of composite materials: II - A damaged-based notched strength model. Composites Science and Technology, 39:303-326, 1990.

[11] MT Kortschot, PWR Beaumont and MF Ashby. Damage mechanics of composite materials: III - Prediction of damage growth and notched strength. Composites Science and Technology, 40:147-165, 1991.

[12] MT Kortschot and PWR Beaumont. Damage mechanics of composite materials: IV - The effect of lay-up on damage growth and notched strength. Composites Science and Technology, 40:167-179, 1991.

[13] SR Hallett, BG Green, WG Jiang and MR Wisnom. An experimental and numerical investigation into the damage mechanisms in notched composites. Composites: Part A, 40:613-624, 2009.

[14] F Laurin, N Carrere, JF Maire and S Mahdi. Enhanced strength analysis method for composite open-hole plates ensuring design office requirements. Composites: Part B, 62:5-11, 2014.

[15] MR Wisnom and FK Chang. Modelling of splitting and delamination in notched crossply laminates. Composites Science and Technology, 60:2849-2856, 2000.

[16] S Sihn, RY Kim, K Kawabe, SW Tsai. Experimental studies of thin-ply laminated composites. Compos Sci Technol, 67:996-1008, 2007.

[17] T Yokozeki, Y Aoki, T Ogasawara. Experimental characterization of strength and damage resistance properties of thin-ply carbon fiber/toughened epoxy laminates. Compos Struct, 82:382-9, 2008.

[18] A Arteiro, G Catalanotti, J Xavier, PP Camanho. Notched response of non-crimp fabric thin-ply laminates. Compos Sci Technol, 79:97-114, 2013.

[19] R Amacher, J Cugnoni, J Botsis, L Sorensen, W Smith, C Dransfeld. Thin ply composites: Experimental characterization and modeling of size-effects. Compos Sci Technol, 101:121-32, 2014.

[20] Y Nishikawa, K Okubo, T Fujii, K Kawabe. Fatigue crack constraint in plainwoven CFRP using newlydeveloped spread tows. Int J Fatigue, 28:1248-53, 2006.

[21] C Furtado, A Arteiro, G Catalanotti, J Xavier, PP Camanho, Selective ply-level hybridisation for improved notched response of composite laminates, Composite Structures 145:1-14, 2016. 
[22] Y Swolfs, L Gorbatikh, I Verpoest. Stress concentrations in hybrid unidirectional fibre-reinforced composites with random fibre packings. Compos Sci Technol, 85:10-16, 2013.

[23] Y Swolfs, L Gorbatikh, I Verpoest. Fibre hybridisation in polymer composites: a review, Compos Part A Appl Sci Manuf, 67:181-200, 2014.

[24] Czél G, Wisnom MR. Demonstration of pseudo-ductility in high performance glass-epoxy composites by hybridisation with thin-ply carbon prepreg. Compos Part A Appl Sci Manuf 2013;52:23-30.

[25] G Czél, M Jalalvand, MR Wisnom. Design and characterisation of advanced pseudo-ductile unidirectional thin-ply carbon/epoxy- glass/epoxy hybrid composites. Compos Struct, V 143:362-370, 2016.

[26] MR Wisnom, G Czél, Y Swolfs, M Jalalvand, L Gorbatick, I Verpoest. Hybrid effects in thin ply carbon/glass unidirectional laminates: accurate experimental determination and prediction, Compos Part A Appl Sci Manuf, V $88: 131-139,2016$.

[27] M Jalalvand, G Czél, MR Wisnom. Damage analysis of pseudo-ductile thin-ply UD hybrid composites - A new analytical method. Compos Part A Appl Sci Manuf, 69:83-93, 2015.

[28] M Jalalvand, G Czél, MR Wisnom. Numerical modelling of the damage modes in UD thin carbon/glass hybrid laminates. Compos Sci Technol; 94:39-47, 2014.

[29] G. Czél, T. Rév, M. Jalalvand, M. Fotouhi, M. Longana, O. Nixon-Pearson, MR. Wisnom. Pseudo-ductility and reduced notch sensitivity in multi-directional all-carbon/epoxy thin-ply hybrid composites, Composites Part A: Applied Science and Manufacturing, 104: 151-164, 2018.

[30] M Jalalvand, M Fotouhi, MR Wisnom. Orientation-dispersed pseudo-ductile hybrid composite laminates A new lay-up concept to avoid free-edge delamination, Composites Science and Technology, 153: 232-240, 2017.

[31] M Fotouhi, M Jalalvand, MR Wisnom, High performance quasi-isotropic thin ply carbon/glass hybrid composites with pseudo-ductile behaviour in all fibre orientations, Composites Science and Technology, 152: 101-110, 2017.

[32] S. R. Hallett, M. R. Wisnom, Numerical Investigation of Progressive Damage and the Effect of Layup in Notched Tensile Tests, Journal of Composite Materials, 40: 14, 1229-1245, 2016.

[33] R. A. Schapery, Thermal Expansion Coefficients of Composite Materials Based on Energy Principles, Journal of Composite Materials, 2: 3, 380-404, 1968.

[34] Czel, G., Jalalvand, M., \& Wisnom, M. R. (2015). Pseudo-ductile carbon/epoxy hybrid composites. In Proceedings of the 20th International Conference on Composite Materials (ICCM20). [3317-1] International Conference on Composite Materials, ICCM.[35] T300 Data Sheet - No. CFA-001. n.d. (http://www.toraycfa.com/pdfs/T300DataSheet.pdf).

[36] Czel, G., Jalalvand, M., \& Wisnom, M. R. (2017). Design and characterisation of high performance pseudoductile all-carbon/epoxy unidirectional hybrid composites. Composite Part B: Engineering; 111:348-356.

[37] MR Wisnom, G Czél, Y Swolfs, M Jalalvand, L Gorbatikh, I Verpoest. Hybrid effects in thin ply carbon/glass unidirectional laminates: Accurate experimental determination and prediction. Compos Part A, 88:131-139, 2016.

[38] SG Lekhnitskii, Anisotropic plates. Gordon and Breach, 1968.

[39] SC Tan. Finite-width correction factors for anisotropic plate containing a central opening, J. of Composite

Materials, 22:1080-18, 1988. 
[40] X Xu, MR Wisnom, Y Mahadik, SR Hallett, An experimental investigation into size effects in quasiisotropic carbon/epoxy laminates with sharp and blunt notches, Composites Science and Technology, 100, 220$227,2014$.

[41] M Fotouhi, M Ahmadi. Acoustic Emission based study to characterize the initiation of mode I delamination in composite materials. Journal of Thermoplast Composite Materials, DOI: 10.1177/0892705713519811, 2014.

[42] M Fotouhi, M Saeedifar, S Sadeghi, M Ahmadi, G Minak. Investigation of the damage mechanisms for mode I delamination growth in foam core sandwich composites using Acoustic Emission. Struct Health Monit, DOI: 10.1177/1475921714568403, 2015.

[43] M Fotouhi, M Ahmadi. Investigation of the mixed-mode delamination in polymer-matrix composites using acoustic emission technique. Journal of Reinforced Plastic Composites, 33 (19): 1767-1782, 2014.

[44] M Fotouhi, P Suwarta, M Jalalvand, G Czel, MR Wisnom. Detection of fibre fracture and ply fragmentation in thin-ply UD carbon/glass hybrid laminates using acoustic emission, Composites Part A: Applied Science and Manufacturing, doi:10.1016/j.compositesa.2016.04.003, 2016. 